\title{
Pricing participating longevity-linked life annuities: a Bayesian Model Ensemble approach
}

\author{
Jorge Miguel Bravo ${ }^{1}$
}

Received: 15 October 2019 / Revised: 14 October 2020 / Accepted: 21 April 2021 /

Published online: 13 May 2021

(c) EAJ Association 2021

\begin{abstract}
Participating longevity-linked life annuities (PLLA) in which benefits are updated periodically based on the observed survival experience of a given underlying population and the performance of the investment portfolio are an alternative insurance product offering consumers individual longevity risk protection and the chance to profit from the upside potential of financial market developments. This paper builds on previous research on the design and pricing of PLLAs by considering a Bayesian Model Ensemble of single population generalised age-period-cohort stochastic mortality models in which individual forecasts are weighted by their posterior model probabilities. For the valuation, we adopt a longevity option decomposition approach with risk-neutral simulation and investigate the sensitivity of results to changes in the asset allocation by considering a more aggressive lifecycle strategy. We calibrate models using Taiwanese (mortality, yield curve and stock market) data from 1980 to 2019. The empirical results provide significant valuation and policy insights for the provision of a cost effective and efficient risk pooling mechanism that addresses the individual uncertainty of death, while providing appropriate retirement income and longevity protection.
\end{abstract}

Keywords Longevity-linked life annuities · Longevity options · Bayesian Model Ensemble $\cdot$ Stochastic mortality models $\cdot$ Pensions

JEL Classification $\mathrm{G} 22 \cdot \mathrm{G} 23 \cdot \mathrm{G} 13 \cdot \mathrm{C} 15$

Jorge Miguel Bravo

jbravo@novaims.unl.pt

1 NOVA IMS Universidade Nova Lisboa, Lisbon, Portugal 


\section{Introduction}

Pension funds and annuity providers face uncertainty regarding financial returns and systematic longevity risk due to unexpected future mortality improvements. Providing a cost effective and efficient risk pooling mechanism that addresses the (individual) uncertainty of death through the provision of a lifetime annuity is one of the main mechanisms pension schemes are considered to redistribute income in a welfare-enhancing manner. Without such an instrument, individuals risk outliving their accumulated (financial, housing, pension) wealth or leaving unintended bequests to his/her dependants. Traditional (level, inflation-indexed) life annuities are a key instrument in mandated Defined Benefit (DB) pension schemes, in financial (FDC) and non-financial Notional (NDC) Defined Contribution schemes and in private pensions provided by insurance companies.

Contrary to the standard Modigliani life-cycle model of savings and consumption prediction, the voluntary market purchase of retirement annuities is in most countries very limited and decreasing and the actual saving/dissaving behaviour after retirement is often at odds with economic theory [39]. Several demand side (e.g., perceived poor value-for-money, the existence of annuity alternatives, bequest motives, behavioural and informational limitations) and supply-side (e.g., the regulatory burden of annuity providers, with onerous capital requirements for unhedgeable risks-e.g., longevity risk-within Solvency II, low to negative central bank interest rates and persistent negative-yielding debt across vast swathes of the global fixed income markets, significant interest rate risk exposure, ${ }^{1}$ long-term financial risk, the cost of loss control and loss financing longevity risk management solutions, limited reinsurance capacity to absorb the massive exposure-to-risk) arguments have been put forward to explain this "annuity puzzle", i.e., to explain why the level of annuitization by individuals is much smaller than economic theory would suggest [47]. Together with the development of capital market longevity-linked securities and their derivatives and innovative reinsurance designs, this has attracted the industry attention towards developing new contract structures with low or no capital guarantees comprising financial and longevity risk sharing mechanisms between the provider and annuitants, and increased recommendations towards the use of deferred annuities, which make the product less expensive by deferring the longevity guarantee and potentially augment their attractiveness to policyholders.

Several alternative index-type and indemnity-type mechanisms have recently been proposed in the literature to share financial and longevity risks (directly or indirectly) between annuity providers and individuals. They typically involve updating the annuity benefit according to observed mortality and investment developments. These products can be divided in two main categories. The first category includes insurance products with partial guarantees and risk-sharing between the provider and the individual. This group includes traditional participating (with-profit) annuities that provide guaranteed lifelong benefits in combination with participation

\footnotetext{
1 See, e.g., Bravo and Silva [10] and Simões et al. [64] for single and multiple ALM interest rate risk immunization strategies for pension funds and annuity providers.
} 
in the insurer's positive surpluses [4], ${ }^{2}$ longevity-linked life annuities $[9,11]$ in which benefits are updated periodically based on the dynamics of both a longevity index and of an interest rate adjustment factor, ${ }^{3}$ longevity-contingent deferred life annuities [27] in which the deferment period can fluctuate according to systematic improvements in mortality while keeping payments fixed once they start, and mortality-index annuities $[45,60]$ in which a contingency fund is set up to reduce the risk of insufficiently funded contracts originated by longevity risk and policyholders participate in surplus due to mortality fluctuations but do not have to cover deficit scenarios. ${ }^{4}$

The second category of products refers to non-insurance (closed or open) pooling arrangements, which merely pool risks among participants, in which no financial or longevity guarantees are explicitly provided by an insurer. This group includes group self-annuitisation (GSA) arrangements [7, 38, 53, 56, 66], in which the provider pools wealth from participants and invests it according to a given investment strategy, a regular income determined by the provider is expected to be paid for life but without any guarantee, and pool participants share both financial, and idiosyncratic and systematic longevity risk. This group includes also pooled annuity funds (PAF) $[8,65]$ which differentiate from a GSA in that participants have freedom in consumption, instead of receiving a benefit determined at inception by the provider. Mortality-linked funds (MLF), which bears some similarities to a PAF but in which the mortality credits being paid are deterministic and not stochastic [31], and annuity overlay funds (AOF) which depart from a PAF in that the fund pools wealth in an investment fund, longevity risk is shared between participants and payout benefits are determined so that the contract is actuarially fair at any instant [30,32], belong also to this category. This category includes modern tontines [35, 48, 49], a selfhedged annuity pool with flexible contributions, heterogenous populations, a customizable annuity plan and additional features like individual unit-linked allocation. As in a standard annuity, there are no benefits paid upon death, and the mortality credits of deceased members are to be allocated among the survival peers.

\footnotetext{
${ }^{2}$ Investment guarantees may be in the form of a "technical interest rate" implicit within the actuarial structure of the product or explicit as a minimum annual return [52]. Blake et al. [4] propose participating annuities which pay survivor credits to annuitants according to the mortality experience of a given pool of annuitants.

3 A similar but narrower approach can be found in Denuit et al. [26] in which only the systematic component of longevity risk is passed to annuitants and caps and floors can be introduced to limit the profitloss share. A related approach is found in Bravo et al. [15] in which annuity payments are updated only if observed survivorship rates exceed a given threshold. Lüthy et al. [44] suggest updating benefits based on the ratio between the annuity factor computed at contract inception and the one based on the latest mortality forecast.

${ }^{4}$ Alternative ways of sharing longevity risk have also been proposed in the context of the design and reform of public pension schemes, e.g., introducing periodically revised annuities in NDC pension schemes in which benefits are updated periodically based on the relationship between expected and observed life expectancy [1], conditional indexation in collective DC plans [5] or NDB/NDC schemes [14], the reform project of the first pillar in Belgium with the adoption of a points system with Musgrave rule [28], the automatic balancing mechanism in NDC schemes (Sweden), two-tier benefit schemes and group-specific annuities $[2,12]$.
} 
Recent proposals include hybrid structures combining tontine-like payments with annuity-like payments after a fixed switching time [22], and tontines providing minimum guaranteed payments in which if the underlying tontine payment performs worse than the fixed guaranteed amount the insurer makes up the difference [23,33]. These later arrangements have some similarities with capped participating longevity-linked life annuities (PLLA) in that they guarantee a minimum income stream for life while allowing policyholders to obtain a higher mortality credit if survivorship is lower than anticipated, and in that their payoff can be decomposed into a sequence of fixed guaranteed amounts and European-style call options on a tontine (in pure PLLA the underlying asset is a longevity index), the main differences being that: (1) they are indemnity-type structures instead of index-type arrangements in which the surviving policyholders bear both the systematic and the unsystematic longevity risk of the participant's pool (particularly at old ages), (2) the arrangement is asymmetric in that only surplus is shared among policyholders, and (3) only biometric risk is shared between the provider and policyholders, whereas in PLLAs financial risk is also shared.

Against this background, this paper builds on the previous work of Bravo and El Mekkaoui de Freitas [11] on the design and pricing of participating longevity-linked life annuities (PLLA) by considering a novel methodological approach for the modelling of longevity risk accounting for the uncertainty in the model selection process (model risk). Contrary to previous studies that often use a single deemed to be the «true» or «best» model to forecast mortality rates, selected from the set of candidate models using some method or criteria, this paper adopts an alternative approach based on a Bayesian Model Ensemble (BME) of six well-known parametric single population Generalised Age-Period-Cohort (GAPC) stochastic mortality models, all of which probabilistically contribute towards projecting future age-specific mortality rates, survival probabilities and PLLA prices. Bayesian model-ensemble or averaging is an application of Bayesian theory to model selection and inference under model uncertainty that involves training several baseline models and the use of rules to combine them together to make predictions. Ensemble methods reduce model risk and the errors resulting from flawed assumptions, bias or errors in the data and account for additional sources of risk not captured in a single model framework. The BME used in this paper combines individual forecasting models by weighting according to each model's forecasting accuracy as measured by the symmetric mean absolute percentage error (SMAPE). For each GAPC model, the SMAPE was estimated using a backtesting exercise using a common "lookback window" and a 5-year forecasting horizon ("lookforward window").

For the valuation of the contract, we adopt the longevity option decomposition approach developed by Bravo and El Mekkaoui de Freitas [11] and extended by Bravo and Nunes [13], the latter using a Fourier transform approach for Europeanstyle longevity option pricing under continuous-time affine jump-diffusion models for both cohort mortality intensities and interest rates. The setting comprises a riskneutral, frictionless, and continuous financial market in which the annuity provider invests the insurance premium in a portfolio of dividend-paying stocks and coupon bonds, and a risk-free interest rate. We assume the yield curve dynamics is well captured by a two-factor equilibrium Vasicek [67] model and the stock market index 
follows a standard geometric Brownian motion diffusion process. To account for the longevity risk premium in pricing the contracts, we compute cohort-specific riskadjusted survival probabilities by using a risk-neutral simulation approach using the Wang distortion operator. We provide empirical results for alternative risk-sharing annuity arrangements, including capped PLLAs that limit benefit volatility and provide longevity insurance. We assume individuals want to optimize the expected present value of utility derived from consumption (annuity income) through their remaining lifetime and compute the fair value of the utility-equivalent fixed life annuity that delivers the same lifetime utility as the PLLA, considering for alternative time preference and risk aversion parameters. We investigate and discuss the sensitivity of empirical results against alternative longevity risk premium values.

Previous empirical studies typically assume the annuity provider follows a constant conservative asset allocation strategy. This paper builds on previous work by investigating the sensitivity of the valuation results to changes in the investment strategy by considering a more aggressive lifecycle strategy in which the percentage allocated to dividend-paying stocks declines linearly from 70 to $30 \%$ over a 30 -year investment horizon. The sensitivity of results to changes in the guaranteed interest rate is also considered. We use Taiwanese (mortality, yield curve and stock market) data from January 1980 to June 2019 to calibrate the models. Previous studies have focused on the development of innovative annuity contracts in mature European or North American markets. In this paper we focus instead on an emerging and high potential Asia Pacific annuity market in which building post-retirement income is a rising issue due to life expectancy developments and public and private pension system reforms.

The empirical results show that: (1) policyholders entering a PLLA contract offering a benefit for life but sharing (at least partially) longevity and investment risks with the policyholder should be offered at a lower price when compared to a traditional level annuity; (2) limiting the upside potential and the downside risk in capped PLLA contracts to $20 \%$ of the initial annuity benefit mitigates annuitant's payment volatility and consumption uncertainty while allowing providers to share most of their systematic longevity risk exposure with policyholders; (3) deferred PLLAs reduce the cost of guarantees and are a cheaper solution to individual longevity risk management; (4) individuals with low risk aversion and low intertemporal preference value positively the chance to profit from right tail financial market developments in participating PLLAs; (5) adopting a riskier lifecycle asset allocation strategy increases expected annuity payments and benefit volatility, an outcome that is positively prized by patient and low risk aversion policyholders.

The development of innovative risk-sharing life annuities is important for consumers, for public and private annuity providers and for the society as whole. For consumers, PLLAs are an interesting decumulation product offering longevity risk protection by guaranteeing payments for life at a lower cost when compared with expensive level annuities, while enjoying (at least partially) the upside potential of positive financial market developments. For annuity providers, PLLAs are better aligned with the current low and persistent negative yield environment, include embedded longevity and financial options which reduce the capital requirements required to cope with the guarantees, mitigating the need for scarce and costly reinsurance or capital market longevity risk solutions. For the society, tackling the current demand and supply constraints which 
hinder the development of annuity markets and the provision of a cost effective and efficient risk pooling mechanism that addresses the individual uncertainty of death, while providing appropriate retirement income and longevity protection, is crucial as part of recent pension reform approaches targeting the development of multipillar solutions to retirement income provision, strengthening of contributory principles and actuarial fairness on a lifetime basis (e.g., the shift from DB to DC arrangements). The remainder of the paper is organized as follows. In Sect. 2, we briefly describe the benefit structure and risk sharing design of PLLAs and introduce the valuation setup. Section 3 describes the financial and stochastic mortality models adopted to empirically investigate the fair value of the contracts, describing in detail the Bayesian Model Ensemble approach to mortality forecasting. In Sect. 4 we analyse and discuss the simulation results for the fair value of participating and non-participating PLLAs and embedded longevity options and investigate the robustness of the results against changes in some key models and parameters. Section 5 concludes and provides guidance for further research.

\section{The setup}

\subsection{Benefit structure and risk sharing design}

Let $T_{x}(t)$ denote a non-negative random variable representing the remaining lifetime of an individual aged $x$ on his/her last birthday at time $t$. We consider the time interval $[0, \omega]$, with $\omega$ denoting the highest attainable age. Define the stochastic force of mortality $\mu_{x}(t)$ of an individual aged $x$ at time $t$ on a filtered probability space. The survival function can be written as follows

$$
S(t, T, x):=E\left[\exp \left(-\int_{t}^{T} \mu_{x+s}(s) d s\right) \mid \mathcal{M}_{t}\right],
$$

where $\mathcal{M}_{t}$ is the filtration generated by the evolution of the stochastic force of mortality up to time $t$. For the discretized stochastic process, we assume that $\mu_{x+\xi}(t+\epsilon)=\mu_{x}(t)$ for any $0 \leq \xi, \epsilon<1$, from which the mortality intensity is approximated by the central death rate $m_{x}(t)$ and $p_{x}(t)=\exp \left(-m_{x}(t)\right)$.

Consider an index-type participating longevity-linked life annuity (PLLA) along the lines proposed by Bravo and El Mekkaoui de Freitas [11]. Under this contract, the annuity benefit is updated periodically based on both the observed survival experience of a reference pool and the investment performance of the financial assets backing the contract. Without loss of generality, let us assume that annuitants contribute equal amounts into the annuity fund and, in return, receive equal annuity benefit payments $b_{t}$ at time $t$. The authors show that the annual benefit at some future date $t_{0}+k, b_{t_{0}+k}$, will depart from the initial benefit $b_{t_{0}}$ depending on the dynamics of both a longevity factor $\mathcal{I}_{t_{0}+k}$ and an interest rate adjustment (IRA) factor $\mathcal{R}_{t_{0}+k}$,

$$
b_{t_{0}+k}=b_{t_{0}} \times \mathcal{I}_{t_{0}+k} \times \mathcal{R}_{t_{0}+k}, \quad k=1, \ldots, \omega-x_{0},
$$


where $\mathcal{I}_{t_{0}+k}$ is a ratio between the expected survival probability and the survival rate observed in a reference population, defined by

with ${ }_{k} p_{x_{0}}^{\left[\mathcal{F}_{t_{0}}\right]}\left(t_{0}\right)$

$$
\mathcal{I}_{t_{0}+k}=\frac{{ }_{k} p_{x_{0}}^{\left[\mathcal{F}_{t_{0}}\right]}\left(t_{0}\right)}{{ }_{k} p_{x_{0}}^{\left[\mathcal{F}_{t_{k}}\right]}\left(t_{k}\right)}=\prod_{j=0}^{k-1} \frac{p_{x_{0}+j}^{\left[\mathcal{F}_{t_{0}}\right]}\left(t_{0}+j\right)}{p_{x_{0}+j}^{\left[\mathcal{F}_{t_{k}}\right]}\left(t_{0}+j\right)},
$$

$$
{ }_{k} p_{x_{0}}^{\left[\mathcal{F}_{t_{0}}\right]}\left(t_{0}\right)=\prod_{j=0}^{k-1}\left[1-q_{x_{0}+j}\left(t_{0}+j\right)\right],
$$

denoting the $k$-year survival probability of some reference population cohort aged $x_{0}$ at time $t_{0}\left(\mathcal{F}_{t_{0}}\right.$ measurable, i.e., computed at contract inception on a market or national population life table ${ }^{5}$ ) and ${ }_{k} p_{x_{0}}^{\left[\mathcal{F}_{t_{k}}\right]}\left(t_{k}\right)$ is the corresponding $k$-year survival probability observed at time $t_{k}\left(\mathcal{F}_{t_{k}}\right.$ measurable). In (3) $q_{x_{0}+j}\left(t_{0}+j\right)$ is the 1-year death probability of an individual aged $x_{0}+j$ at time $t_{0}+j$. If ${ }_{k} p_{x_{0}}^{\left[\mathcal{F}_{t_{0}}\right]}$ is measured in a reference population we have an index-type contract, whereas if ${ }_{k} p_{x_{0}}^{\left[\mathcal{F}_{t_{0}}\right]}$ is measured in the target annuity or pension fund portfolio we have an indemnity-type structure. The IRA factor $\mathcal{R}_{t_{0}+k}$ is defined by

$$
\mathcal{R}_{t_{0}+k}=\frac{\prod_{t=1}^{k}\left(1+R_{t_{0}+t}\right)}{\left(1+i_{t_{0}}\right)^{k}}
$$

where $R_{t_{0}+t}$ denotes the observed net investment return in year $t>t_{0}$ and $i_{t_{0}}$ is the (non-negative) guaranteed interest rate (GIR) set at time 0 .

If $R_{t_{0}+t}=i_{t_{0}} \forall t$ (i.e., $\mathcal{R}_{t_{0}+k}=1$ ) and mortality improvements are as expected (i.e., $\mathcal{I}_{t_{0}+k}=1 \forall k$ ), the arrangement resembles a classical life annuity with fixedreturn, and fixed-benefit. If $\mathcal{R}_{t_{0}+k}=1$ and observed longevity improvements are higher (lower) than predicted, i.e., $\mathcal{I}_{t_{0}+k}<1(>1) \forall k$, annuity payments will decline (increase) along with the dynamics of $\mathcal{I}_{t_{0}+k}$. If mortality improvements are as expected and investments perform above the GIR (i.e., $\mathcal{R}_{t_{0}+k}>1 \forall k$ ), the extra return is paid back to participants in the form of a higher benefit payment. If $\mathcal{I}_{t_{0}+k}<1$ and $\mathcal{R}_{t_{0}+k}>1$, the better than expected investment returns may at least partially compensate the negative impact of higher than expected mortality improvements. At annuity inception, the longevity and the IRA indexes are random variables

\footnotetext{
${ }^{5}$ To reduce basis risk, the mortality dynamics of the reference population should be closely linked to that of the target annuity portfolio or pension fund.
} 
and, hence, future annuity benefits are uncertain. This contrasts with traditional level annuity contracts that guarantee a constant benefit as long as the annuitant is alive, independently of longevity and financial market developments, transferring all risks (financial and biometric) to the provider.

Appropriate bounds to the longevity and IRA adjustment factors (or to the benefit amount) can in principle be introduced to offer partial guarantees, limit the volatility of annuity payments, to provide effective longevity insurance or to limit the profitshare (e.g., caps and floors, longevity corridors, partial participation mechanisms, a maximum age to apply the benefit adjustment). ${ }^{6}$ For instance, in Denuit et al. [26] and Bravo and El Mekkaoui de Freitas [11] the authors suggest to limit the risk beared by policyholders by adding (possibly) time-dependent upper $\mathcal{I}_{t_{0}+k}^{\max }(t)$ and lower $\mathcal{I}_{t_{0}+k}^{\min }(t)$ barriers for the longevity index, i.e., $0<\mathcal{I}_{t_{0}+k}^{\min }(t)<1<\mathcal{I}_{t_{0}+k}^{\max }(t)$. In the particular case caps and floors are constant during the whole contract we have $\mathcal{I}_{t_{0}+k}^{\max }(t)=\mathcal{I}^{\text {max }}$ and $\mathcal{I}_{t_{0}+k}^{\min }(t)=\mathcal{I}^{\text {min }}$ for $k=1, \ldots, \omega-x_{0}$. In a capped PLLA the longevity index is replaced by its capped version

$$
\mathcal{I}_{t_{0}+k}\left(\mathcal{I}_{t_{0}+k}^{\min }, \mathcal{I}_{t_{0}+k}^{\max }\right)=\max \left\{\min \left(\mathcal{I}_{t_{0}+k} ; \mathcal{I}_{t_{0}+k}^{\max }\right) ; \mathcal{I}_{t_{0}+k}^{\min }\right\}
$$

From (1) it is clear that in a PLLA annuity benefits are adjusted upwards (downwards) depending on whether the observed survival probability is higher (lower) than predicted at contract inception and the realized investment return is above (below) the guaranteed interest rate. ${ }^{7}$

The PLLA is a standardized index-based contract using reference (e.g., national) population mortality data with some advantages over the customized contracts (e.g., participating life annuities), particularly its simplicity, transparency, cost and greater potential for liquidity. However, they also carry some shortcomings, chiefly the fact that they expose the provider to residual basis risk due to adverse selection that typically characterizes the annuity market. The magnitude of the basis risk depends on the extent to which the longevity improvements of the reference population and the annuitants' portfolio experience diverge over time. To reduce basis risk, the mortality dynamics of the reference population should be closely correlated to that of the target annuity portfolio or pension fund. The impact of compositional changes - changes in the distribution of

\footnotetext{
${ }^{6}$ Note that in life insurance contracts including risk-sharing mechanisms (e.g., participating annuities), the determination of the actual mortality and investment surplus generated by the insurer and the percentage to be distributed to annuitants often depend on national insurance codes and the supervising authority. For instance, in Germany the Minimum Profit-Sharing Act (MindZV) establishes that the minimum amount that has to be shared with the annuitants is $90 \%$ of asset returns, $75 \%$ of mortality returns, and $50 \%$ of other return sources [46].

7 The risk (and profit)-sharing mechanism can further be limited by specifying at contract inception a maximum age to apply the benefit adjustment (1), $x_{b}^{\max }$, eventually in combination with caps and floors. In this case, the annuity benefits evolve over time as follows:

$$
b_{t_{0}+k}= \begin{cases}b_{t_{0}} \times \mathcal{I}_{t_{0}+k} \times \mathcal{R}_{t_{0}+k}, & k=1, \ldots, x_{b}^{\max }-x_{0} \\ b_{t_{0}+x_{b}^{\max }-x_{0}}, & k=x_{b}^{\max }-x_{0}+1, \ldots, \omega-x_{0}\end{cases}
$$

i.e., the contract structure combines a temporary PLLA with maturity $x_{b}^{\max }-x_{0}$ with a deferred life annuity with unknown benefit at time 0 .
} 
the population across age, sex and socio-economic groups - on aggregated and groupspecific mortality rates induced by ageing and heterogeneity in longevity are important since they influence the size and dynamics of basis risk and the redistributive consequences of the contract [55]. In addition to the structural effects of longevity heterogeneity, the different mortality risks of individuals lead to cohort, selection and mortality displacement effects $[62,68]$. For instance, in each cohort the proportion of individuals possessing (genetic, health, lifestyle) characteristics related to higher mortality decreases over time, while the proportion of those who hold characteristics associated with lower mortality increases. In the event of adverse selection effects between the reference population and the insured portfolio, annuitants are thus expected to deviate more from the reference population at earlier ages and less at older ages.

\subsection{Valuation}

Consider a filtered probability space $(\Omega, \mathbb{F}, \mathbb{P})$ large enough to support the dynamics of the stochastic mortality process $\mu_{x}(t)$, the stochastic discounting interest rate $r_{t}$ and the stochastic IRA factor $\mathcal{R}_{t}$. We define the joint filtration generated by the longevity and interest rate adjustment factors and the discounting interest rate as $\mathcal{F}_{t}:=\mathcal{M}_{t} \vee \mathcal{D}_{t} \vee \mathcal{G}_{t}=\sigma\left(\mathcal{M}_{t} \cup \mathcal{D}_{t} \cup \mathcal{G}_{t}\right)$ where $\mathcal{G}_{t}$ is the filtration generated by the evolution of $\mathcal{R}_{t}$ up to time $t$ and $\mathcal{D}_{t}$ is the filtration generated by the evolution of the discounting interest rate up to time $t$.

Without loss of generality, consider an immediate PLLA contract with initial benefit $b_{t_{0}}=1$ offered to an individual aged $x_{0}$ at time $t_{0}$ with remaining lifetime $T_{x_{0}}\left(t_{0}\right)=\omega-x_{0}$. The $\mathcal{F}_{t_{0}}$-measurable fair value (single premium) of this contract at time $t_{0}$ is given by

$$
a_{x_{0}}^{P L L A}\left(t_{0}\right)=\sum_{k=1}^{\omega-x_{0}} E^{\mathbb{Q}}\left[D F\left(t_{0}, t_{0}+k\right) \cdot{ }_{k} p_{x_{0}}^{\left[\mathcal{F}_{t_{k}}\right]}\left(t_{k}\right) \cdot \mathcal{I}_{t_{0}+k} \cdot \mathcal{R}_{t_{0}+k} \mid \mathcal{F}_{t_{0}}\right],
$$

where $D F(t, T)$ is a (stochastic) exponential discount factor defined as

$$
D F(t, T)=\exp \left(-\int_{t}^{T} r_{u} d u\right)
$$

with $\left\{r_{t}: t \geq 0\right\}$ the stochastic discounting interest rate process, and $\mathbb{Q}$ the risk-neutral measure.

In the particular case $\mathcal{R}_{t_{0}+k}=1$, all of the systematic longevity risk is transferred to annuitants and a pure PLLA is obtained. If $\mathcal{I}_{t_{0}+k}=\mathcal{R}_{t_{0}+k}=1(\forall k)$ the design (6) is equivalent to that of a classical level annuity. ${ }^{8}$ Similarly, the fair value of an immediate capped PLLA (CPLLA) can be expressed as follows

${ }^{8}$ The fair value of a deferred PLLA due with initial benefit $b_{t_{0}}=1$ payable from time $t_{0}+u$ to an individual then aged $x_{0}+u$ is given by

$$
{ }_{u l} \ddot{a}_{x_{0}}^{\text {PLLA }}\left(t_{0}\right)=\sum_{k=u}^{\omega-x_{0}-u} E^{\mathbb{Q}}\left[D F\left(t_{0}, t_{0}+k\right) \cdot{ }_{k} p_{x_{0}}^{\left[\mathcal{F}_{t_{k}}\right]}\left(t_{k}\right) \cdot \mathcal{I}_{t_{0}+k} \cdot \mathcal{R}_{t_{0}+k} \mid \mathcal{F}_{t_{0}}\right]
$$




$$
\begin{aligned}
& a_{x_{0}}^{C P L L A}=\sum_{k=1}^{\omega-x_{0}} E^{\mathbb{Q}} \\
& \quad \times\left[D F\left(t_{0}, t_{0}+k\right) \cdot{ }_{k} p_{x_{0}}^{\left[\mathcal{F}_{t_{k}}\right]}\left(t_{k}\right) \cdot \max \left(\min \left(\mathcal{I}_{t_{0}+k} ; \mathcal{I}_{t_{0}+k}^{\max }\right) ; \mathcal{I}_{t_{0}+k}^{\min }\right) \cdot \mathcal{R}_{t_{0}+k} \mid \mathcal{F}_{t_{0}}\right] .
\end{aligned}
$$

The premium (8) represents the fair value of the systematic financial and longevity risks retained by the annuity provider.

\subsection{Pricing by longevity option decomposition}

In this paper we use the pioneering results derived in Bravo and El Mekkaoui de Freitas [11] for the valuation of participating longevity-linked life annuities via longevity option decomposition. Consider, for instance, a scenario in which observed longevity improvements are higher than predicted and investment performance matches the guaranteed interest rate, i.e., $\mathcal{I}_{t_{0}+k}<1$ and $\mathcal{R}_{t_{0}+k}=1$ for $k=1, \ldots, \omega-x_{0}$. The annuity benefit at time $t_{0}+k$ can be expressed in terms of the maturity payoff of an 'auto executable' European-style put option with underlying the longevity index and strike the initial benefit amount, i.e.,

$$
b_{t_{0}+k}=b_{t_{0}}\left[1-\left(1-\mathcal{I}_{t_{0}+k}\right)^{+}\right]
$$

where $a^{+}:=\max (a, 0)$ is the positive part of $a \in \mathbb{R}$. Assume, without loss of generality, that $b_{t_{0}}=1$. The fair value of a PLLA at time $t_{0}$ can be decomposed into a long position in a classical level annuity $a_{x_{0}}^{\left[\mathcal{F}_{t_{0}}\right]}\left(t_{0}\right)$ and a short position in an embedded European-style longevity floor $\mathcal{L}^{F}\left(t_{0}\right)$ with underlying $\mathcal{I}_{t_{0}+k}$, constant strike equal to one unit of currency and maturity $\omega-x_{0}$, i.e., ${ }^{9}$

$$
a_{x_{0}}^{P L L A}\left(t_{0}\right)=a_{x_{0}}^{\left[\mathcal{F}_{t_{0}}\right]}\left(t_{0}\right)-\mathcal{L}^{F}\left(t_{0}\right)
$$

with

$$
\mathcal{L}^{F}\left(t_{0}\right)=\sum_{k=1}^{\omega-x_{0}} E^{\mathbb{Q}}\left[D F\left(t_{0}, t_{0}+k\right) \cdot_{k} p_{x_{0}}^{\left[\mathcal{F}_{t_{k}}\right]}\left(t_{0}\right) \cdot\left(1-\mathcal{I}_{t_{0}+k}\right)^{+} \mid \mathcal{F}_{t_{0}}\right]
$$

Similar to a standard interest rate floor, the longevity floor can be decomposed into a portfolio of European-style longevity floorlets with common constant strike and maturities matching the annuity payment dates. The longevity floor offers the

\footnotetext{
9 In a symmetrically designed contract in which annuity payments can also increase if observed longevity improvements are lower than predicted, Bravo and Freitas [11] show that the fair value of a PLLA can be decomposed into a long position in a classical fixed annuity, a long position in an embedded European-style longevity cap and a short position in an embedded European-style longevity floor with underlying $\mathcal{I}_{t_{0}+k}$, constant strike equal to one unit of currency and maturity $\omega-x_{0}$.
} 
annuity provider protection from losses arising due to faster than expected mortality improvements. Compared to a classical annuity, the contract transfers longevity risk to policyholders, which accept to take the risk in exchange for a reduced annuity premium (equal to the longevity floor price). ${ }^{10}$

In a scenario in which observed longevity improvements are consistently worse than anticipated (i.e., $\mathcal{I}_{t_{0}+k}>1, \forall k$ ) and portfolio returns match the GIR, the fair value of a PLLA at time $t_{0}$ can be decomposed into a long position in a level annuity and a long position in an auto-callable European-style longevity call $\mathcal{L}^{C}\left(t_{0}\right)$ with underlying $\mathcal{I}_{t_{0}+k}$ and strike price $b_{t_{0}}$, i.e.,

$$
a_{x_{0}}^{P L L A}\left(t_{0}\right)=a_{x_{0}}^{\left[\mathcal{F}_{t_{0}}\right]}\left(t_{0}\right)+\mathcal{L}^{C}\left(t_{0}\right)
$$

with

$$
\mathcal{L}^{C}\left(t_{0}\right)=\sum_{k=1}^{\omega-x_{0}} E^{\mathbb{Q}}\left[D F\left(t_{0}, t_{0}+k\right){ }_{k} p_{x_{0}}^{\left[\mathcal{F}_{t_{k}}\right]}\left(t_{0}\right) \cdot\left(\mathcal{I}_{t_{0}+k}-1\right)^{+} \mid \mathcal{F}_{t_{0}}\right] .
$$

Individuals assessing the possibility of annuitizing their wealth but with disbelief about their longevity prospects may feel attracted to buy a PLLA if they were given the chance to increase annuity payments if their predictions are confirmed. In other words, Eq. (14) shows that individuals willing to have this option should pay an additional premium $\mathcal{L}^{C}\left(t_{0}\right)$ (or accept a lower initial benefit when compared to level annuities) to hold a series of call options on the underlying asset. ${ }^{11}$ In the more general case in which the PLLA shares both longevity risk and positive investment surpluses, i.e., in which $\mathcal{I}_{t_{0}+k}<1$ and $\mathcal{R}_{t_{0}+k}>1$, the biometric and financial adjustment factors have (full/partial) compensating effects on future annuity payments benefits.

${ }^{10}$ Similarly, for a deferred PLLA due with a deferral period of $u$ years, the fair value of the annuity and embedded deferred longevity floor can be computed as follows

$$
\begin{aligned}
& { }_{u} \ddot{a}_{x_{0}}^{P L L A}\left(t_{0}\right)={ }_{u \mid} \ddot{a}_{x_{0}}^{\left[\mathcal{F}_{t_{0}}\right]}\left(t_{0}\right)-\mathcal{L}_{u}^{F}\left(t_{0}\right) \\
& \text { with } \\
& \mathcal{L}_{u}^{F}\left(t_{0}\right)=\sum_{k=u}^{\omega-x_{0}-u} E^{\mathbb{Q}}\left[D F\left(t_{0}, t_{0}+k\right) \cdot_{k} p_{x_{0}}^{\left[\mathcal{F}_{t_{k}}\right]}\left(t_{0}\right) \cdot\left(1-\mathcal{I}_{t_{0}+k}\right)^{+} \mid \mathcal{F}_{t_{0}}\right]
\end{aligned}
$$

For a capped PLLA, Bravo and El Mekkaoui [11] suggest three equivalent decompositions for the annuity payoff: (1) a protective longevity collar, i.e., a portfolio comprising the underlying, a long position in a longevity floorlet with strike $\mathcal{I}_{t_{0}+k}^{\min }$ and a short position in a longevity caplet with strike $\mathcal{I}_{t_{0}+k}^{\max } ;(2) \mathrm{A}$ long position in a longevity caplet spread, i.e., a portfolio comprising the minimum benefit, a long position in a longevity caplet with strike $\mathcal{I}_{t_{0}+k}^{\min }$ and a short position in a longevity caplet with strike $\mathcal{I}_{t_{0}+k}^{\max }$; (3) A short position in a longevity floorlet spread, i.e., a portfolio comprising the maximum benefit, a long position in a longevity floorlet with strike $\mathcal{I}_{t_{0}+k}^{\min }$ and a short position in a longevity floorlet with strike $\mathcal{I}_{t_{0}+k}^{\max }$.

11 In a symmetrically designed contract in which annuity payments can decrease (increase) if observed longevity improvements are higher (lower) than predicted, the fair value of a PLLA can be decomposed into a long position in a classical fixed annuity, a long position in an embedded European-style longevity cap and a short position in an embedded European-style longevity floor with underlying $\mathcal{I}_{t_{0}+k}$, constant strike equal to one unit of currency and maturity $\omega-x_{0}$. 


\section{Materials and methods}

We devise a model to investigate the pricing and the welfare of individuals in a retirement scheme with market-provided participating longevity-linked life annuities. The framework comprises a Bayesian Model Ensemble of generalised age-period-cohort stochastic mortality models to forecast the survival prospects and a financial market with a risk-free asset and stochastic stock and bond markets.

\subsection{Mortality forecasting: a Bayesian Model Ensemble approach}

Traditionally, mortality rate forecasting has been based on a single deemed to be the «true» or «best » model, selected from the set of candidate models using some method or criteria (e.g., information criteria (AIC, BIC), forecasting accuracy measure), often neglecting the uncertainty in the model selection process (model risk) for statistical inference purposes. To address this problem, in this paper we adopt an alternative approach based on a Bayesian Model Ensemble (BME) or averaging of six well-known parametric single population Generalised Age-Period-Cohort (GAPC) stochastic mortality models, all of which probabilistically contribute towards projecting future age-specific mortality rates, survival probabilities and PLLA prices. Bayesian model-ensemble or averaging is an application of Bayesian theory to model selection and inference under model uncertainty. Ensemble learning methods train several baseline models and use rules to combine them together to make predictions. It is an innovative statistical approach to inference in the presence of multiple competing statistical models. The approach overcomes the problem of drawing conclusions based on a unique model by conditioning the statistical inference on the entire set of statistical models initially considered in the analysis (or a subset of them). When compared to a single model, ensemble learning has demonstrated to improve traditional and machine learning forecasting results and has been widely applied in social and health science areas [14].

Let each candidate model be denoted by $M_{l}, l=1, \ldots, K$ representing a set of probability distributions comprehending the likelihood function $L\left(y \mid \theta_{l}, M_{l}\right)$ of the observed data $y$ in terms of model specific parameters $\theta_{l}$ and a set of prior probability densities for said parameters $p\left(\theta_{l} \mid M_{l}\right)$. Consider a quantity of interest $\Delta$ present in all models, such as the future observation of $y$. The law of total probability tells us that its marginal posterior distribution across all models is given by

$$
p(\Delta \mid y)=\sum_{k=1}^{K} p\left(\Delta \mid y, M_{k}\right) p\left(M_{k} \mid y\right),
$$

where $p\left(\Delta \mid y, M_{k}\right)$ denotes the forecast PDF based on model $M_{k}$ alone, and $p\left(M_{k} \mid y\right)$ is the posterior probability of model $M_{k}$ given the observed data ("lookforward window" in case of time series), thus reflecting how well model $M_{k}$ fits the training data. The posterior probability for model $M_{k}$ is given by 


$$
p\left(M_{k} \mid y\right)=\frac{p\left(y \mid M_{k}\right) p\left(M_{k}\right)}{\sum_{l=1}^{K} p\left(y \mid M_{l}\right) p\left(M_{l}\right)},
$$

where

$$
p\left(y \mid M_{k}\right)=\int L\left(y \mid \theta_{k}, M_{k}\right) p\left(\theta_{k} \mid M_{k}\right) d \theta_{k},
$$

is the integrated likelihood of model $M_{k}$. The posterior model probabilities add up to one, i.e., $\sum_{k=1}^{K} p\left(M_{k} \mid y\right)=1$ and can be interpreted as weights. The Bayesian Model Ensemble PDF is a weighted average of the PDFs given the individual models, weighted by their posterior model probabilities [43, 57].

To determine which models received a greater or lesser weight in the final forecast, for each subpopulation we first rank the models according to their out-of-sample predictive accuracy. We carry out a backtesting exercise in the spirit of Dowd et al. [34] and use the forecast error in mortality rates as measured by the symmetric mean absolute percentage error (SMAPE) to assess the forecasting accuracy. The SMAPE for model $k$ and subpopulation $g$ is defined by

$$
S M A P E_{k}, g=\frac{1}{n_{x, t}} \sum_{x=x_{\min }}^{x_{\max }} \sum_{t=t_{\min }}^{t_{\max }} \frac{\left|\dot{\mu}_{x, t, g}-\mu_{x, t, g}\right|}{0.5 \times\left(\dot{\mu}_{x, t, g}+\mu_{x, t, g}\right)},
$$

where $\dot{\mu}_{x, t, g}$ and $\mu_{x, t, g}$ denote the point forecast and observed mortality rates, respectively, and $n_{x, t}=\left(x_{\max }-x_{\min }+1\right)\left(t_{\max }-t_{\min }+1\right)$. Second, we compute the model weights using the "Softmax" (normalized exponential) function as follows

$$
p\left(M_{k} \mid y\right)=\frac{\exp \left(-\left|\xi_{k}\right|\right)}{\sum_{l=1}^{K} \exp \left(-\left|\xi_{l}\right|\right)}
$$

with

$$
\xi_{k}=\frac{S_{k}}{\max \left\{S_{l}\right\}_{l=1, \ldots, K}}, \quad k=1, \ldots, K,
$$

where $S_{k}$ is the SMAPE value for model $k$. The Softmax function is a generalization of the logistic function that transforms a $K$-dimensional vector of arbitrary real values to a $k$-dimensional vector of real values in the range $[0,1]$ that adds up to one. The Softmax function is often used in classification and forecasting exercises using traditional, machine learning and deep learning methods as a combiner or an activation function [63]. The function assigns larger weights to models with smaller forecasting error, with the weights decaying exponentially the larger the error. ${ }^{12}$ Finally, in step 3 given the model's posterior probability (weights), the BME point forecast

\footnotetext{
12 Alternative choices for the posterior probability allocation include, for example, the normalized C-probability, the natural odds-based probability, the extreme C-probability, the normalized extreme C-probability or the Sigmoid function.
} 
of mortality rates is obtained by probabilistically combining the $K$ individual models using Eq. (16).

GAPC stochastic mortality models are a class of parametric models that link a response variable with a linear or bilinear predictor structure consisting of a series of factors dependent on age of the individual, $x$; period effects, $t$; and year of birth (or cohort) effects, $c=t-x$. The model's structure includes a random and a systematic components, a link function, a set of parameter constraints to ensure identifiability and time series methods for forecasting and simulating the period and cohort indexes $[41,69]$. The random component specifies whether the number of deaths recorded at age $x$ during calendar year $t, D_{x, t}$, follows a Poisson distribution $D_{x, t} \sim \mathcal{P}\left(\mu_{x, t} E_{x, t}^{c}\right)$, with $\mathbb{E}\left(D_{x, t} / E_{x, t}^{c}\right)=\mu_{x, t}$, or a Binomial distribution $D_{x, t} \sim \mathcal{B}\left(q_{x, t} E_{x, t}^{0}\right)$, with $\mathbb{E}\left(D_{x, t} / E_{x, t}^{0}\right)=q_{x, t}$, where $E_{x, t}^{0}$ and $E_{x, t}^{c}$ denote, respectively, the population initially or centrally exposed-to-risk, and $q_{x, t}$ is the 1-year death probability for an individual aged $x$ last birthday in year $t$. The systematic component links a response variable (e.g., $q_{x, t}$ or $\mu_{x, t}$ ) to an appropriate linear predictor $\eta_{x, t}$, capturing the general shape of mortality across all ages and other time invariant features of the mortality curve, the determinants of the evolution of mortality rates through time, the pattern of mortality change across ages and systematic year-of-birth effects,

$$
\eta_{x, t}=\alpha_{x}+\sum_{i=1}^{N} \beta_{x}^{(i)} \kappa_{t}^{(i)}+\beta_{x}^{(0)} \gamma_{t-x}
$$

where $\exp \left(\alpha_{x}\right)$ denotes the general shape of the mortality schedule across age, $\beta_{x}^{(i)} \kappa_{t}^{(i)}$ is a set of $N$ age-period terms describing the mortality trends, with each time index $\kappa_{t}^{(i)}$ contributing in specifying the general mortality trend and $\beta_{x}^{(i)}$ modulating its effect across ages, and the term $\gamma_{t-x} \equiv \gamma_{c}$ accounts for the cohort effect $c$ with $\beta_{x}^{(0)}$ modulating its effect across ages. The age modulating coefficients $\beta_{x}^{(i)}$ can be preset or non-parametric terms to be estimated, e.g., as in the Lee-Carter model. The period indexes $\kappa_{t}^{(i)}$ and the cohort index $\gamma_{t-x}$ are stochastic processes. The link function $g$ connects the random component and the systematic component, i.e., $g\left(\mathbb{E}\left(D_{x, t} / E_{x, t}\right)\right)=\eta_{x, t}$, typically following the canonical link, i.e., matching the Poisson distribution with the log-link function and the Binomial distribution with the logit-link function. The specification is complemented with a set of parameter constraints to ensure unique parameter estimates.

Table 1 summarizes the structure of the six GAPC stochastic mortality models used in this study. The set of models includes: [LC] the standard age-period Lee-Carter model under a Poisson setting for the number of deaths and using the log-link function with respect to $\mu_{x, t}[16,59]$; [APC] the age-period-cohort model proposed by Currie [24]; [RH] the generalization of the Lee-Carter model by incorporating cohort effects with particular substructure obtained by setting $\beta_{x}^{(0)}=1[37,58]$ and additional approximate identifiability constraint on the parameters of the model to improve the robustness and convergence rate [42]; [CBD] the Cairns-Blake-Dowd model considering a predictor structure with two age-period terms, pre-specified age-modulating parameters $\beta_{x}^{(1)}=1$ and $\beta_{x}^{(2)}=(x-\bar{x})$, with $\bar{x}$ 
Table 1 Structure of the GAPC stochastic mortality models used in this study

\begin{tabular}{lll}
\hline Model & Predictor & Original reference \\
\hline LC & $\eta_{x, t}=\alpha_{x}+\beta_{x}^{(1)} \kappa_{t}^{(1)}$ & Brouhns et al. [16] \\
APC & $\eta_{x, t}=\alpha_{x}+\kappa_{t}^{(1)}+\gamma_{t-x}$ & Currie [24] \\
RH & $\eta_{x, t}=\alpha_{x}+\beta_{x}^{(1)} \kappa_{t}^{(1)}+\beta_{x}^{(0)} \gamma_{t-x}$ & Renshaw and Haberman [58] \\
CBD & $\eta_{x, t}=\kappa_{t}^{(1)}+(x-\bar{x}) \kappa_{t}^{(2)}$ & Cairns et al. [18] \\
M7 & $\eta_{x, t}=\kappa_{t}^{(1)}+(x-\bar{x}) \kappa_{t}^{(2)}+\left((x-\bar{x})^{2}-\sigma\right) \kappa_{t}^{(3)}+\gamma_{t-x}$ & Cairns et al. [17] \\
Plat & $\eta_{x, t}=\alpha_{x}+\kappa_{t}^{(1)}+(x-\bar{x}) \kappa_{t}^{(2)}+(\bar{x}-x)^{+} \kappa_{t}^{(3)}+\gamma_{t-x}$ & Plat [55] \\
\hline
\end{tabular}

the average age in the data, no cohort effects, assuming a Binomial distribution of deaths and using a logit-link function targeting 1-year death probabilities $q_{x, t}$ [18]; [M7] an extension of the original CBD model with cohort effects and a quadratic age effect [17], called M7 in Dowd et al. [34]; and [Plat] the three period factor model proposed by Plat [55] incorporating the dependence between ages with particular substructure obtained by setting $\kappa_{t}^{(3)}=0$ since we are interested only in older ages. These models were selected to incorporate the age, period and cohort features of mortality rates across different countries and ages and because they have proven to perform well in fitting and forecasting exercises (see, e.g., [34]). Parameter estimates are obtained using maximum-likelihood (ML) methods.

To forecast age-specific mortality rates, we first calibrate the models using Taiwanese male population data from 1980 to 2014 and for ages in the range 50-95. Mortality data is obtained from the Human Mortality Database [40]. The historical "lookback window" is set from 1980 to 2009 for all models and a 5-year forecasting horizon ("lookforward window") is considered. To forecast and simulate mortality rates, we assume the age vectors $\alpha_{x}$ and $\beta_{x}^{(i)}$ remain constant over time and model period indices $\kappa_{t}^{(i)}$ using a multivariate random walk with a drift. Cohort indices $\gamma_{t-x}$ were modelled with univariate ARIMA models [37]. Finally, to close the prospective life tables at high ages $(x \geq 90)$ and to establish the highest attainable age $\omega$, the simple and efficient method proposed by Denuit and Goderniaux [25] is applied. The method consists of fitting by OLS the following log-quadratic model

$$
\ln \hat{q}_{x}(t)=a_{t}+b_{t} x+c_{t} x^{2}+\epsilon_{x}(t), \quad \epsilon_{x}(t) \sim \mathcal{N}\left(0, \sigma^{2}\right),
$$

to age-specific mortality rates observed at older ages, separately for each calendar year $t$, with two additional constraints: (1) $q_{\omega}(t)=1$; (2) $\left.\frac{\delta}{\delta x} q_{x}(t)\right|_{x=\omega}=0$. The ultimate age is set as $\omega=125$ for all years and subpopulations. ${ }^{13}$

Figure 1 plots the crude mortality rates by year (1980-2014) and age (50-95) for Taiwan's male population. We can observe a clear downward trend in the mortality rates at all ages and years, more pronounced in the age range 60-85.

\footnotetext{
${ }^{13}$ The method is applied before pricing so that the resulting probabilities are risk adjusted using the Wang distortion operator for pricing purposes.
} 

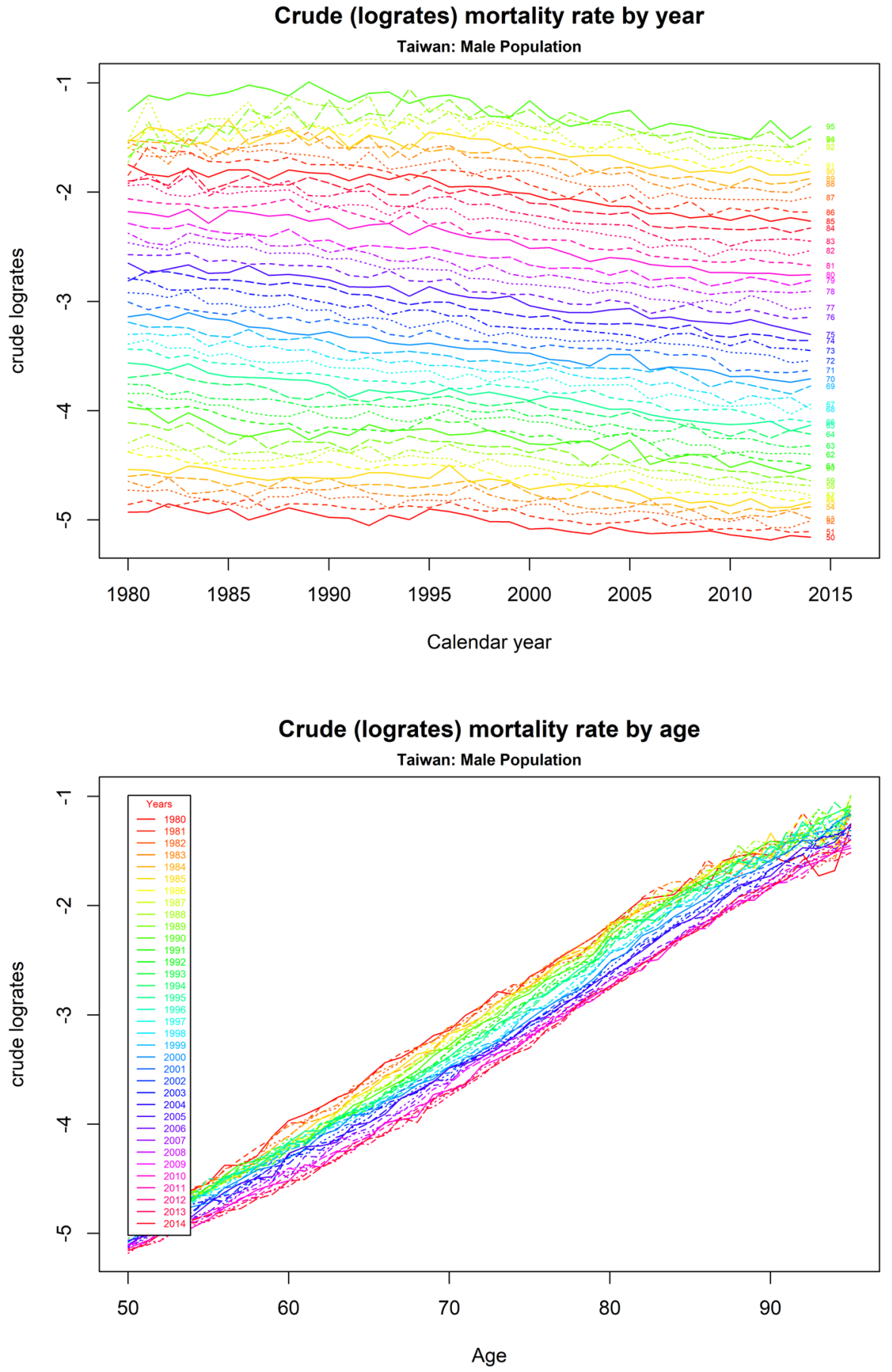

Fig. 1 Taiwan: Crude mortality rates by year (1980-2014) and age (50-95), male population 
Figure 2 plots the individual GAPC forecasted (log) mortality rates over the period 2010-2100 and ages 50-95 for the same population. The six models forecast that the survival prospects of the Taiwanese male population will continue to improve at all ages, with slight differences in terms of mortality improvement rates and across ages. Figure 3 plots the BME model weights computed using the Softmax function (20). The figure reveals that the LC model ranked first in terms of forecasting accuracy in the sample lookforward window used in this study, followed by the CBD and APC models. The RH, Plat and M7 models exhibit the higher SMAPE values in the sample under study, receiving lower posterior model probabilities in the BME combination.

In GAPC stochastic mortality models, the uncertainty regarding future mortality rates is merely a result of the uncertainty about the future values of the period and cohort indices. For pricing purposes, we need to consider the market price of longevity risk. Since the underlying longevity index is not an existing tradable asset in a liquid market, we use a distortion operator to create an equivalent risk-adjusted probability distribution for $q_{x, t}$ or $p_{x, t}$ to compute the fair value of the derivative security, an approach recommended when pricing long-term contracts $[3,36] .{ }^{14}$ To be more specific, we use the flexible risk-neutral simulation approach proposed by Boyer and Stentoft [6] using the classical Wang transform as a risk measure [70-72]. This method involves risk-neutralizing the innovations in the stochastic mortality models used to represent mortality process risk using the Wang distortion operator $\lambda$. In the simulations, this involves using random draws for $\epsilon_{t}$ from a $\epsilon \sim N\left(-\lambda \sigma, \sigma^{2}\right)$ distribution instead of using draws from a $\epsilon \sim N\left(0, \sigma^{2}\right)$ distribution, recursively generating simulations for the level period indices, which are then replaced back into the GAPC models to obtain risk-adjusted mortality rate forecasts. For a given parameter $\lambda \in[0,0.3]$, a simulation consists of generating $N=10,000$ trajectories for the BME cohort survival probability and for the longevity index (2). Figure 4 presents a fan plot of the simulated survival probability of a cohort aged 50 in 2014 over 10,000 replications.

\subsection{Financial market}

In a risk-neutral, frictionless and continuous financial market, the baseline scenario assumes the annuity provider invests the insurance premia collected into a portfolio of dividend-paying stocks (30\%) and straight 10-year coupon bonds (70\%). Regular bond coupon and dividend payments are invested in a riskless short-term bank account until the next (annual) portfolio rebalancing period. At the beginning of each year, the insurance company pays annuitants' benefits from asset income and from assets sold at market prices. Depending on the insurer's mortality and investment experience, annuitants may receive surplus payments in addition to their guaranteed return. This surplus

\footnotetext{
14 Alternative approaches have been proposed to price longevity-linked securities, including the arbitrage-free pricing framework of interest-rate derivatives, using the instantaneous Sharpe ratio, adopting the Equivalent Utility Pricing Principle, the CAPM- and CCAPM-based approaches or the cost of capital approach.
} 
LC

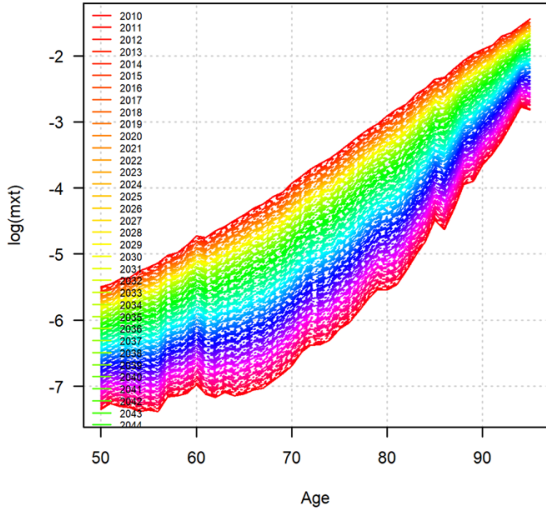

CBD

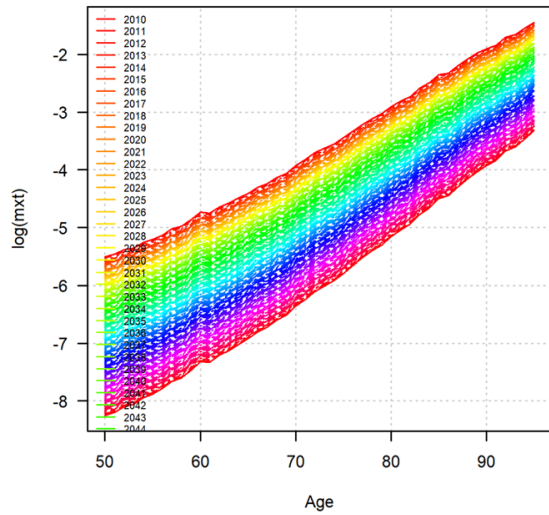

M7

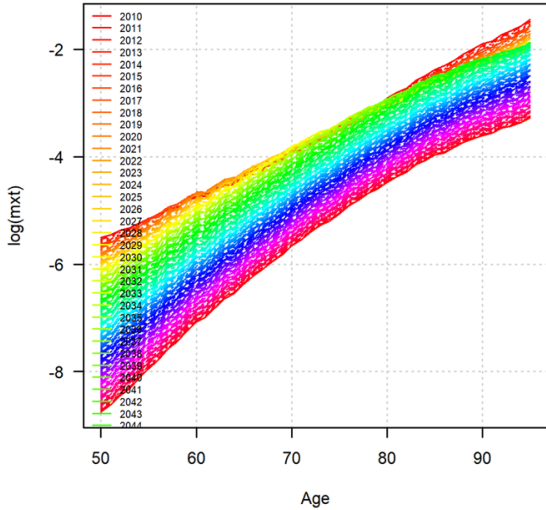

APC

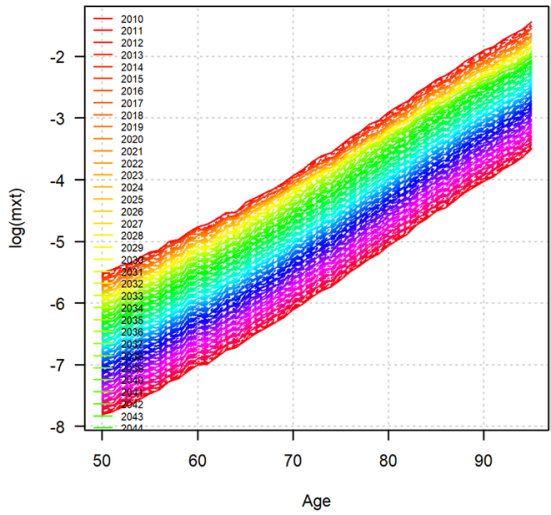

Plat

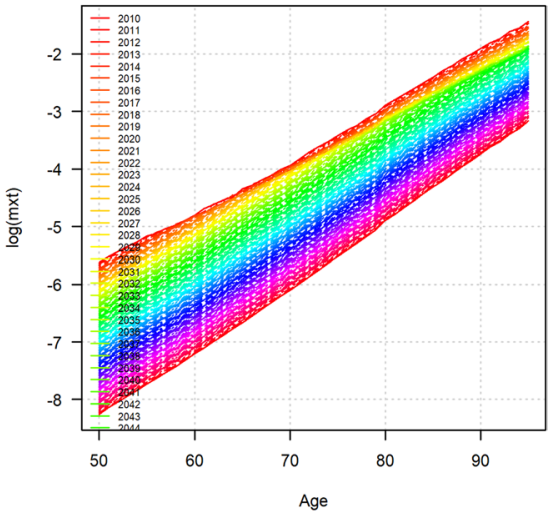

$\mathrm{RH}$

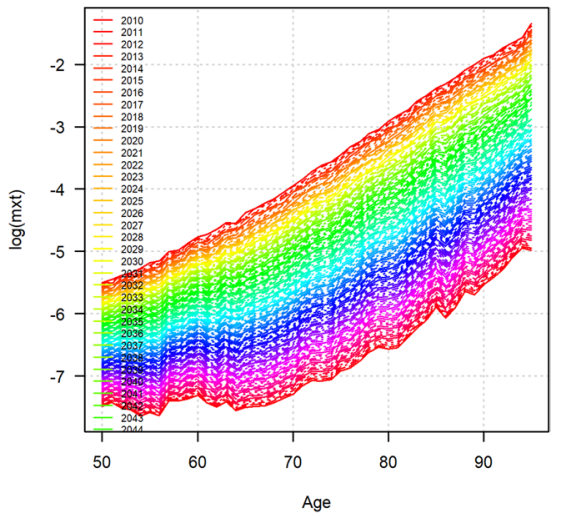

Fig. 2 Individual GAPC model forecasted mortality rates (male population) 
TWN

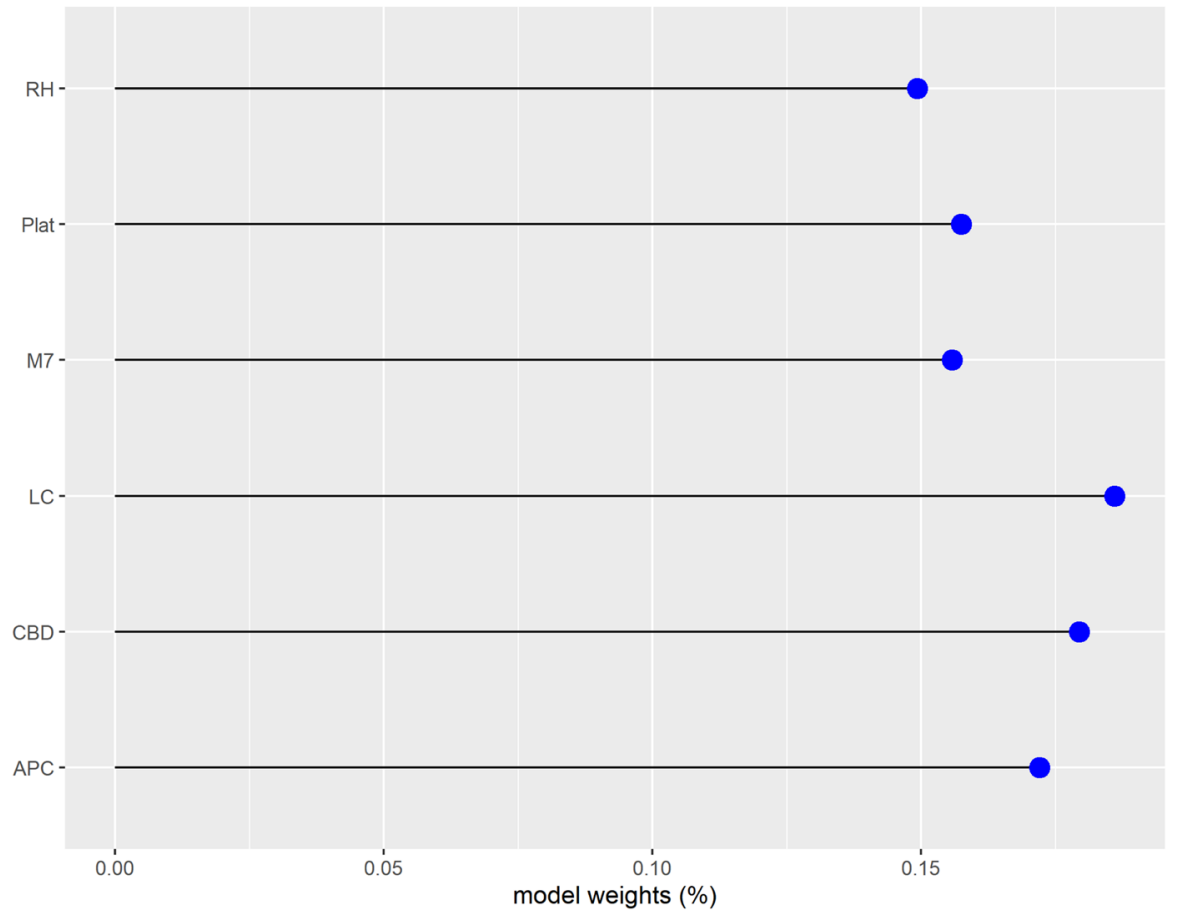

Fig. 3 BME model weights (male population)

is generated when observed policyholder mortality exceeds that assumed at contract inception, and/or when total investment return exceeds the guaranteed return. We assume that the insurer's solvency capital always exceeds a pre-specified solvency limit such that the period's total surplus can be fully paid out to annuitants.

We assume the yield curve dynamics is well captured by a two-factor equilibrium Vasicek [67] model. The model proved to explain significantly more yield curve shifts that are observed at the market than its one-factor variant [29]. The model assumes that $r_{t}$ is a sum of two independent Ornstein-Uhlenbeck processes $x_{t}$ and $y_{t}$ (generally modelled as the short-term rate and the long-term rate)

$$
\begin{aligned}
r_{t} & =x_{t}+y_{t} \\
d x_{t} & =\beta_{x}\left(\mu_{x}-x_{t}\right) d t+\sigma_{x} d W_{1}(t) \\
d y_{t} & =\beta_{y}\left(\mu_{y}-y_{t}\right) d t+\sigma_{y} d W_{2}(t),
\end{aligned}
$$

where $r(0)=x_{0}+y_{0}, x(0)=x_{0}, y(0)=y_{0}$, and $\left(W_{1}, W_{2}\right)$ is a two-dimensional Brownian motion with instantaneous correlation $\rho(-1 \leq \rho \leq 1)$,

$$
d W_{1}(t) d W_{2}(t)=\rho,
$$

where $x_{0}, y_{0}, \beta_{x}, \beta_{y}, \mu_{x}, \mu_{y}, \sigma_{x}, \sigma_{y}$ are positive constants. 


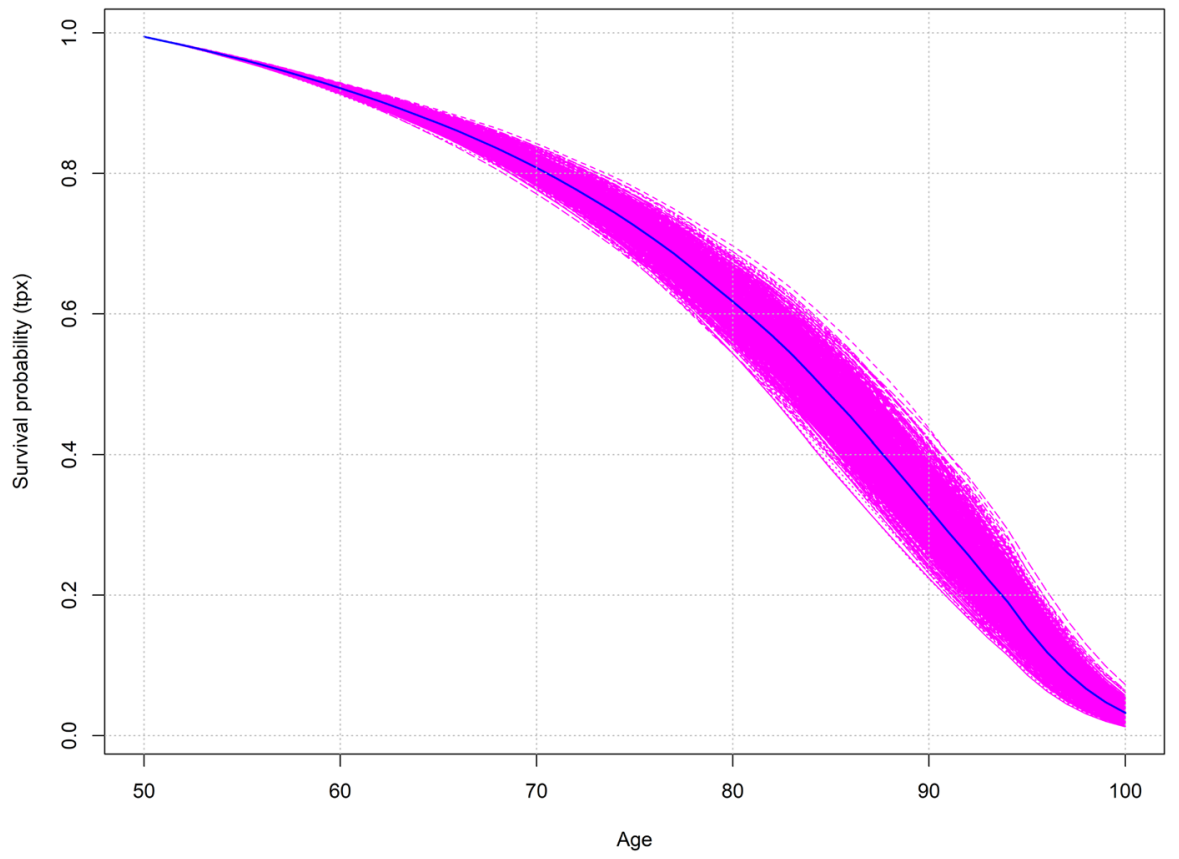

Fig. 4 Fan plot of simulated survival probability of the male cohort aged 50 in 2014

The model allows for closed-formulas for the price of zero-coupon and coupon paying bonds. From (24), it can be shown that the spot interest rate at time $t$ with maturity $T, r(t, T)$, is given by

$$
\begin{aligned}
r(t, T)= & \mu_{x}+\frac{\left(1-e^{\beta_{x} \tau}\right)}{\beta_{x} \tau}\left(x_{t}-\mu_{x}\right)+\mu_{y}+\frac{\left(1-e^{\beta_{y} \tau}\right)}{\beta_{y} \tau}\left(y_{t}-\mu_{y}\right) \\
& -\frac{\sigma_{x}^{2}}{2 \beta_{x}^{2}}\left(1+\frac{1-e^{-\beta_{x} \tau}}{2 \beta_{x} \tau}-2 \frac{1-e^{-\beta_{x} \tau}}{\beta_{x} \tau}\right) \\
& -\frac{\sigma_{y}^{2}}{2 \beta_{y}^{2}}\left(1+\frac{1-e^{-\beta_{y} \tau}}{2 \beta_{y} \tau}-2 \frac{1-e^{-\beta_{y} \tau}}{\beta_{y} \tau}\right) \\
& -\frac{\rho \sigma_{x} \sigma_{y}}{\beta_{x}+\beta_{y}}\left(1-\frac{1-e^{\beta_{x} \tau}}{\beta_{x} \tau}-\frac{1-e^{\beta_{x} \tau}}{\beta_{x} \tau}+\frac{1-e^{-\left(\beta_{x}+\beta_{y}\right) \tau}}{\left(\beta_{x}+\beta_{y}\right) \tau}\right),
\end{aligned}
$$

where $\tau=T-t$, and bond prices $B(t, T)$ can be computed as follows

$$
B(t, T)=e^{-r(t, T)(T-t)} .
$$

To calibrate the yield curve model, we use daily data on Taiwan 2- and 10-year maturity bond yields from January 2000 to June 2019. Estimates of the short rate and the long-rate stochastic processes are obtained using ML methods (Table 2). 
Table 2 Estimates of the 2-factor Vasicek model (note: data source Datastream)

\begin{tabular}{llll}
\hline & $\beta_{i}$ & $\mu_{i}$ & $\sigma_{i}$ \\
\hline Short rate $x_{t}$ & 0.8486580 & 0.8815142 & 0.6930047 \\
Long rate $y_{t}$ & 0.1493086 & 2.3225287 & 0.3526179 \\
\hline
\end{tabular}

We estimate that $\hat{\rho}=0.4342177$, which means the short- and long-term sections of the yield curve are positively but not perfectly correlated. We assume the value of the stock market index at time $t$, which is denoted by $S_{t}$, follows a standard geometric Brownian motion diffusion process

$$
\frac{d S_{t}}{S_{t}}=\mu d t+\sigma d W_{t},
$$

where $W_{t}$ is a standard Wiener process with respect to the real world probability measure; $\mu$ and $\sigma$ denote, respectively, the instantaneous stock price drift and volatility. The dynamics of stock prices is calibrated to the TSEC weighted index stock market data over the same period considering the index values adjusted for dividends and splits. The ML parameter estimates are $(\hat{\mu}, \hat{\sigma})=(0.03433942,0.21188526)$.

\subsection{Welfare analysis}

We assume that at time $t$ individuals want to maximize the expected present value of utility derived from consumption through their remaining lifetime. We assume that the PLLA benefits constitute the individual's only source of income and that individuals ignore bequest motives since the contract makes payments only if the annuitant is alive. Assuming the annuitant's preferences can be described by a standard time additive constant relative risk aversion (CRRA) utility function defined over consumption, the optimization problem can be expressed as follows:

$$
V_{t}=\max _{C_{t}, C_{t+1}, \ldots, C_{\omega-x}} \mathbb{E}_{t}\left[\sum_{k=t}^{\omega-x} \beta^{k}\left\{{ }_{k} p_{x} \frac{C_{t}^{1-\gamma}}{1-\gamma}\right\}\right],
$$

where $\beta>0$ is the subjective discount factor, $\gamma(\gamma \neq 1, \gamma>0)$ is the coefficient of relative risk aversion, $C_{t}$ is the retirement consumption (income) in year $t, \mathbb{E}_{t}$ is the expectation operator at time $t=0$ under the subjective probability measure and the remaining variables keep their previous meaning.

To assess how individuals with different risk aversion and subjective time preferences value the stochastic payout stream from a PLLA and to compute their willingness-to-pay (WTP) for the contract, we compute the utility-equivalent level annuity income, $E A_{t}$, by solving (28) for consumption [51]:

$$
E A_{t}=\left[\frac{(1-\gamma) V_{t}}{\sum_{k=1}^{\omega-x} \beta_{k}^{k} p_{x}}\right]^{\frac{1}{1-\gamma}} .
$$


Finally, taking the level annuity income (29) we compute the fair value of the utilityequivalent fixed life annuity (EFLA) that delivers the same lifetime utility as the PLLA and compare it with that of a level life annuity. In the simulations, we consider three alternative time preference and risk aversion parameters. For the subjective discount factor we consider individuals that are $\beta=0.98$ (patient), $\beta=0.96$ (normal) and $\beta=0.94$ (impatient). For the coefficient of relative risk aversion, we classify policyholders as $\gamma=2$ (low risk), $\gamma=5$ (medium risk) and $\gamma=10$ (high risk).

\section{Results and discussion}

In this section we analyse and discuss the simulation results for the fair value of participating and non-participating longevity-linked life annuities and embedded longevity options taking into account: (1) the age of the policyholder; (2) the magnitude of the longevity risk premium; (3) the existence of bounds for the annuity benefit; (4) the with-profit or non with-profit nature of the contract; (5) the size of guaranteed interest rate (GIR); (6) alternative values for the subjective discount factor and for the coefficient of relative risk aversion.

\subsection{Base case}

In Table 3 we report the mean of the simulated risk-neutral distribution of the annuity and longevity option prices for some representative ages and different values of the market price of longevity risk in the baseline scenario. We assume in this case: (1) a guaranteed interest rate of $0 \%$ per year; (2) the reference life table is given by the mean of the simulated survival trajectories with zero longevity risk premium; (3) the contract is non-participating and pays an initial benefit of one monetary unit per year; and (4) annuity payments are capped at the initial benefit. Each simulation consists of 10,000 independent sample paths for both the survival probability of a cohort aged $x$ in $2014\left\{{ }_{k} p_{x_{0}}(2014): x_{0} \in[50,90]\right\}$ and the portfolio returns. In Table 3 Panel A reports the pure premium $a_{x_{0}}^{\left[\mathcal{F}_{t_{0}}\right]}\left(t_{0}\right)$ of a fixed immediate life annuity purchased at representative ages. Recall that for $i_{t_{0}}=0 \%$, the value of $a_{x_{0}}^{\left[\mathcal{F}_{t_{0}}\right]}\left(t_{0}\right)$ matches that of the remaining life expectancy at age $x_{0}$. The baseline interest rate scenario resembles the current debt market conditions in Taiwan and most G20 and OECD countries. Panels B and C report, respectively, the fair value of the embedded European-style longevity floor options (with constant unit strike price and maturity $\omega-x_{0}$ ) for alternative values of the longevity risk premium in absolute and relative terms (i.e., as a percentage of $a_{x_{0}}^{\left[\mathcal{F}_{t_{0}}\right]}\left(t_{0}\right)$, in basis points), and Panel D reports the fair value of a non-participating PLLA together with the corresponding $95 \%$ confidence interval bounds. 
Table 3 Fair value of non-participating PLLA and embedded longevity floor option prices (notes: $\mathrm{GIR}=0$ percent; Zero risk premium as reference life table; Annuity payments capped at the initial benefit)

\begin{tabular}{|c|c|c|c|c|c|c|c|c|c|}
\hline Age & 50 & 55 & 60 & 65 & 70 & 75 & 80 & 85 & 90 \\
\hline \multicolumn{10}{|c|}{ Panel A: Pure premium of a fixed life annuity } \\
\hline$a_{x_{0}}^{\left[\mathcal{F}_{t_{0}}\right]}\left(t_{0}\right)$ & 32.38 & 27.63 & 23.07 & 18.76 & 14.77 & 11.22 & 8.19 & 5.74 & 3.85 \\
\hline \multicolumn{10}{|c|}{ Panel B: Longevity Floor price $\mathcal{L}^{F}\left(t_{0}\right)$} \\
\hline$\lambda=0.0$ & 0.54 & 0.48 & 0.42 & 0.35 & 0.26 & 0.20 & 0.12 & 0.06 & 0.03 \\
\hline$\lambda=0.1$ & 0.92 & 0.78 & 0.65 & 0.51 & 0.38 & 0.26 & 0.17 & 0.09 & 0.05 \\
\hline$\lambda=0.2$ & 1.38 & 1.16 & 0.93 & 0.72 & 0.53 & 0.35 & 0.21 & 0.11 & 0.05 \\
\hline$\lambda=0.3$ & 1.92 & 1.59 & 1.28 & 0.96 & 0.69 & 0.45 & 0.26 & 0.14 & 0.06 \\
\hline
\end{tabular}

Panel C: $\mathcal{L}^{F}\left(t_{0}\right)$ as a \% of $a_{x_{0}}^{\left[\mathcal{F}_{t_{0}}\right]}\left(t_{0}\right)$ (in b.p)

\begin{tabular}{|c|c|c|c|c|c|c|c|c|}
\hline$\lambda=0.0$ & 167 & 174 & 182 & 184 & 173 & 174 & 147 & 105 \\
\hline$\lambda=0.1$ & 283 & 282 & 280 & 272 & 254 & 227 & 201 & 157 \\
\hline$\lambda=0.2$ & 426 & 418 & 403 & 384 & 355 & 307 & 256 & 183 \\
\hline$\lambda=0.3$ & 593 & 575 & 553 & 512 & 467 & 401 & 311 & 235 \\
\hline
\end{tabular}

Panel D: Pure premium of a non-participating PLLA $a_{x_{0}}^{\text {PLLA }}\left(t_{0}\right)$

\begin{tabular}{llllllllll}
$\lambda=0.0$ (mean) & 31.84 & 27.15 & 22.65 & 18.42 & 14.52 & 11.03 & 8.07 & 5.68 & 3.82 \\
UB 95\% & 33.23 & 28.36 & 23.65 & 19.18 & 15.01 & 11.28 & 8.15 & 5.69 & 3.82 \\
LB 95\% & 30.45 & 25.94 & 21.65 & 17.65 & 14.02 & 10.77 & 7.99 & 5.67 & 3.82 \\
$\lambda=0.1$ (mean) & 31.47 & 26.85 & 22.43 & 18.25 & 14.40 & 10.97 & 8.03 & 5.65 & 3.81 \\
UB 95\% & 33.21 & 28.35 & 23.65 & 19.17 & 14.99 & 11.26 & 8.12 & 5.67 & 3.81 \\
LB 95\% & 29.72 & 25.35 & 21.20 & 17.33 & 13.80 & 10.67 & 7.93 & 5.63 & 3.80 \\
$\lambda=0.2$ (mean) & 32.38 & 26.48 & 22.14 & 18.04 & 14.25 & 10.88 & 7.98 & 5.64 & 3.81 \\
UB 95\% & 34.38 & 28.20 & 23.54 & 19.08 & 14.92 & 11.21 & 8.09 & 5.65 & 3.81 \\
LB 95\% & 30.38 & 24.75 & 20.74 & 17.00 & 13.57 & 10.54 & 7.87 & 5.62 & 3.80 \\
$\lambda=0.3$ (mean) & 30.46 & 26.04 & 21.80 & 17.80 & 14.08 & 10.77 & 7.94 & 5.61 & 3.79 \\
UB 95\% & 32.62 & 27.90 & 23.32 & 18.94 & 14.82 & 11.14 & 8.05 & 5.62 & 3.79 \\
LB 95\% & 28.30 & 24.18 & 20.27 & 16.66 & 13.34 & 10.40 & 7.82 & 5.59 & 3.79 \\
\hline
\end{tabular}

As expected, the fair value of a level annuity $a_{x_{0}}^{\left[\mathcal{F}_{t_{0}}\right]}\left(t_{0}\right)$ is smaller the older the policyholder at contract initiation, i.e., decreases with the reduction in the remaining life expectancy (Panel A). Similarly, the longevity floor prices are increasing in maturity (decreasing with the age of the policyholder at contract inception) and in the market price of risk (Panel B). For instance, for $\lambda=0$ the longevity option price for a 50-year old individual at the end of 2014 is 0.54 , whereas for an equivalent contract starting at age 65 the price is 0.35 . For $\lambda=0.3$, the longevity floor option price increases to 1.92 (0.96) for a 50 (65)-year old individual. The embedded European-style longevity floor prices represent between $0.78 \%$ and $5.93 \%$ of the pure premium of a conventional level annuity (Panel C). This means, for instance, that a 50-year old male individual entering into a non-participating LLA contract should pay a pure single premium $5.93 \%$ smaller than that of an equivalent level annuity (for $\lambda=0.3$ ) to compensate for the chance of annuity benefits declining if 


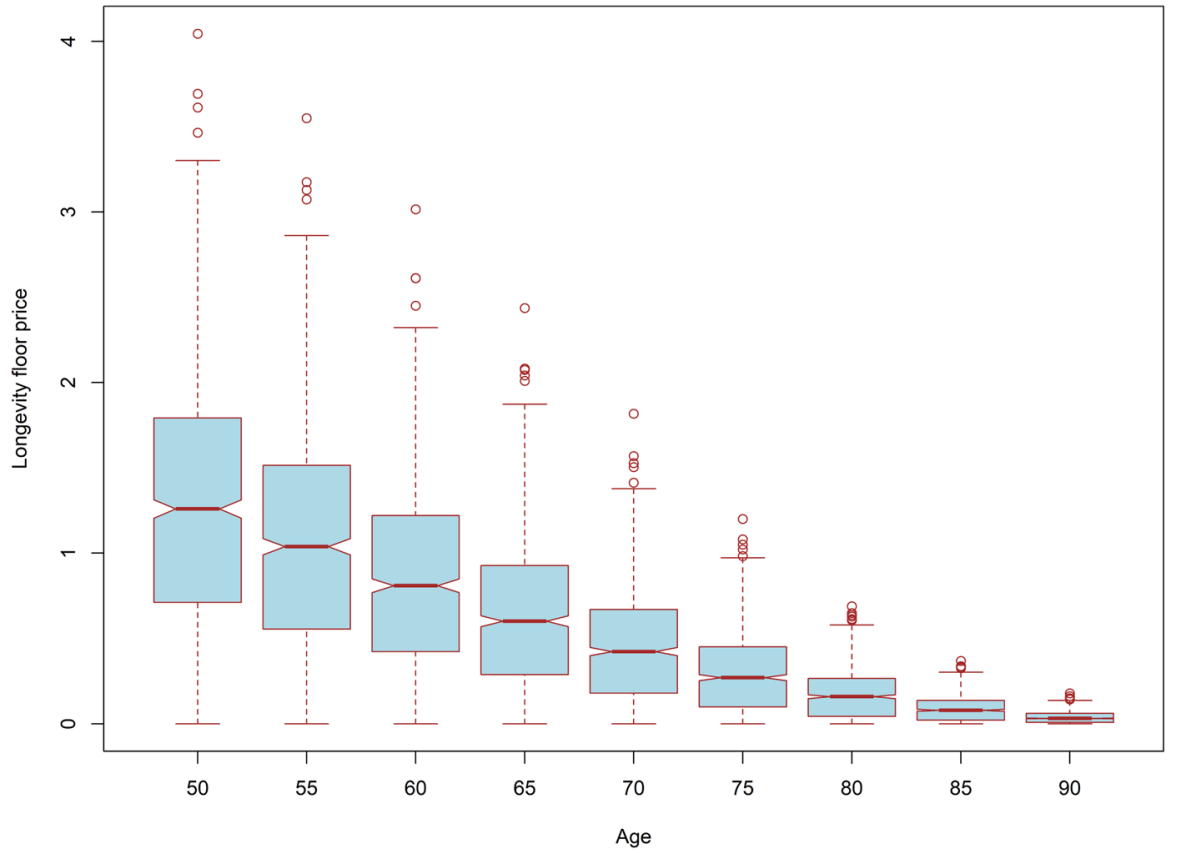

Fig. 5 Boxplot of the simulated risk-neutral distribution of longevity option prices (note: baseline scenario)

observed survivorship rates are higher than predicted. For this representative case, the $95 \%$ confidence interval for the mean estimate of the fair value is [28.30,32.62] with mean estimate 30.46 (Panel D). Figure 5 offers additional insight into the simulated risk-neutral distribution of longevity option prices for $\lambda=0.3$. The variability of option prices is naturally higher at younger ages given the higher uncertainty regarding the remaining lifetime prospects at these ages, decreasing then steadily with age. These results are in line with those obtained in previous studies using data for France, although in this later case the higher trend risk observed in the French population resulted in higher longevity option prices (Fig. 5).

Table 4 reports the mean of the simulated risk-neutral distribution of the pure premium of a deferred non-participating PLLA due assuming a deferment period of 15 years $(u=15)$. The prices of both the fixed and PLLA deferred contracts are now naturally smaller than that of immediate annuities at all ages and values of the market price of longevity risk since the number of potential annuity payments is reduced. For instance, for a 50-year old male individual the fair value of the deferred non-participating PLLA contract is now 55.4\% (16.89) of that of the corresponding immediate annuity (30.46) for $\lambda=0.3$. For contracts initiating at older ages the annuity and longevity option prices decrease substantially and the confidence intervals are narrower since the number of potential annuity payments is smaller, and the survival probabilities are minimal. This makes the product potentially interesting for both providers and annuitants. Empirical studies have shown that retirees are reluctant to convert retirement savings into annuities and that the levels of voluntary 
Table 4 Fair value of nonparticipating deferred PLLAs (notes: GIR $=0$ percent; Zero risk premium as reference life table; Annuity payments capped at the initial benefit)

\begin{tabular}{|c|c|c|c|c|c|c|}
\hline Age & 50 & 55 & 60 & 65 & 70 & 75 \\
\hline \multicolumn{7}{|c|}{ Panel A: Pure premium of a deferred fixed life annuity } \\
\hline$u_{u \mid} \ddot{a}_{x_{0}}^{\left[\mathcal{F}_{t_{0}}\right]}(t$ & 18.51 & 14.01 & 9.88 & 6.27 & 3.40 & 1.45 \\
\hline \multicolumn{7}{|c|}{ Panel B: Deferred longevity floor price $\mathcal{L}_{u}^{F}\left(t_{0}\right)$} \\
\hline$\lambda=0.0$ & 0.46 & 0.40 & 0.33 & 0.25 & 0.16 & 0.08 \\
\hline$\lambda=0.1$ & 0.77 & 0.65 & 0.52 & 0.38 & 0.23 & 0.12 \\
\hline$\lambda=0.2$ & 1.17 & 0.96 & 0.75 & 0.53 & 0.34 & 0.16 \\
\hline$\lambda=0.3$ & 1.63 & 1.33 & 1.03 & 0.73 & 0.44 & 0.21 \\
\hline \multicolumn{7}{|c|}{ Panel $C: \mathcal{L}_{u}^{F}\left(t_{0}\right)$ as a $\%$ of $u \mid \ddot{a}_{x_{0}}^{\left[{ }_{t_{0}}\right]}\left(t_{0}\right)_{(\text {in b.p) }}$} \\
\hline$\lambda=0.0$ & 246 & 288 & 329 & 394 & 459 & 537 \\
\hline$=0.1$ & 414 & 464 & 527 & 601 & 688 & 806 \\
\hline$\lambda=0.2$ & 632 & 687 & 763 & 850 & 994 & 1075 \\
\hline$\lambda=0.3$ & 878 & 947 & 1040 & 1161 & 1300 & 1433 \\
\hline
\end{tabular}

Panel D: Pure premium of a non-participating deferred PLLA $\ddot{a}_{u \mid} \ddot{a}_{x_{0}}^{L L A}\left(t_{0}\right)$

$\begin{array}{lllllll}\lambda=0.0 \text { (mean) } & 18.06 & 13.60 & 9.55 & 6.03 & 3.24 & 1.37 \\ \text { UB 95\% } & 19.45 & 14.82 & 10.56 & 6.79 & 3.74 & 1.62 \\ \text { LB 95\% } & 16.67 & 12.39 & 8.55 & 5.26 & 2.75 & 1.12 \\ \lambda=0.1 \text { (mean) } & 17.75 & 13.36 & 9.36 & 5.90 & 3.17 & 1.33 \\ \text { UB 95\% } & 19.49 & 14.86 & 10.58 & 6.81 & 3.76 & 1.63 \\ \text { LB 95\% } & 16.00 & 11.86 & 8.13 & 4.98 & 2.57 & 1.04 \\ \lambda=0.2 \text { (mean) } & 18.51 & 13.05 & 9.12 & 5.74 & 3.06 & 1.30 \\ \text { UB 95\% } & 20.52 & 14.77 & 10.52 & 6.78 & 3.74 & 1.63 \\ \text { LB 95\% } & 16.51 & 11.32 & 7.72 & 4.70 & 2.39 & 0.96 \\ \lambda=0.3 \text { (mean) } & 16.89 & 12.68 & 8.85 & 5.54 & 2.96 & 1.24 \\ \text { UB 95\% } & 19.05 & 14.54 & 10.37 & 6.69 & 3.70 & 1.61 \\ \text { LB 95\% } & 14.73 & 10.82 & 7.33 & 4.40 & 2.22 & 0.87\end{array}$

annuitization are low. As a result, insurance companies are putting a lot of effort to design more attractive annuity products. Deferred PLLA contracts, eventually incorporating bounds to the annuity benefit to limit the volatility of retirement income, are an interesting solution for the payout phase of pension schemes since it requires a smaller initial investment than immediate PLLAs and provide similar longevity insurance for the oldest-old.

Moving now to contract structures in which the annuity benefit is bounded by some caps and floors, Table 5 reports the monetary prices of European-style longevity floor options embedded in non-participating capped PLLAs for different constant threshold levels and selected ages at contract initiation. For instance, the case $\left[\mathcal{I}_{t_{0}+k}^{\min }, \mathcal{I}_{t_{0}+k}^{\max }\right]=[0.9,1.1]$ corresponds to a PLLA structure with $\mathcal{I}_{t_{0}+k}^{\min }=\mathcal{I}^{\min }=0.9$ and $\mathcal{I}_{t_{0}+k}^{\max }=\mathcal{I}^{\max }=1.1$ for $k=1, \ldots, \omega-x_{0}$, i.e., annuity payments can decline (increase) by a maximum of $10 \%$ of the initial benefit if observed survivorship rates 
Table 5 Capped PLLA: longevity floor option prices (notes: GIR $=0$ percent; Market price of longevity risk parameter equal to 0.3 ; Prices in monetary units)

\begin{tabular}{lllllllllll}
\hline Longevity floor price $\mathcal{L}^{F}\left(t_{0} \mid \mathcal{I}_{t_{0}+k}^{\min }, \mathcal{I}_{t_{0}+k}^{\max }\right)$ \\
\hline Bounds & Age & & & & & & & & & \\
\cline { 2 - 11 } & {$\left[\mathcal{I}_{t_{0}+k}^{\min }, \mathcal{I}_{t_{0}+k}^{\max }\right]$} & 50 & 55 & 60 & 65 & 70 & 75 & 80 & 85 & 90 \\
\hline$[0.9,1.1]$ & 1.31 & 1.11 & 0.90 & 0.71 & 0.53 & 0.36 & 0.23 & 0.12 & 0.06 \\
{$[0.8,1.2]$} & 1.70 & 1.43 & 1.16 & 0.89 & 0.65 & 0.44 & 0.26 & 0.14 & 0.06 \\
{$[0.7,1.3]$} & 1.85 & 1.53 & 1.23 & 0.95 & 0.68 & 0.45 & 0.26 & 0.14 & 0.06 \\
{$[0.6,1.4]$} & 1.89 & 1.58 & 1.26 & 0.96 & 0.68 & 0.45 & 0.26 & 0.14 & 0.06 \\
{$[0.5,1.5]$} & 1.91 & 1.59 & 1.26 & 0.96 & 0.68 & 0.45 & 0.26 & 0.14 & 0.06 \\
{$[0.4,1.6]$} & 1.91 & 1.59 & 1.26 & 0.96 & 0.68 & 0.45 & 0.26 & 0.14 & 0.06 \\
{$[0.3,1.7]$} & 1.92 & 1.59 & 1.28 & 0.96 & 0.69 & 0.45 & 0.26 & 0.14 & 0.06 \\
{$[0.2,1.8]$} & 1.92 & 1.59 & 1.28 & 0.96 & 0.69 & 0.45 & 0.26 & 0.14 & 0.06 \\
{$[0.1,1.9]$} & 1.92 & 1.59 & 1.28 & 0.96 & 0.69 & 0.45 & 0.26 & 0.14 & 0.06 \\
{$[0.0,2.0]$} & 1.92 & 1.59 & 1.28 & 0.96 & 0.69 & 0.45 & 0.26 & 0.14 & 0.06 \\
\hline & & & & & & & & &
\end{tabular}

are higher (lower) than predicted. The case $\left[\mathcal{I}_{t_{0}+k}^{\min }, \mathcal{I}_{t_{0}+k}^{\max }\right]=[0.8,1.2]$ corresponds to a contract in which the downside risk and the upside potential is limited to $20 \%$ of the initial benefit and so on. The case $\left[\mathcal{I}_{t_{0}+k}^{\min }, \mathcal{I}_{t_{0}+k}^{\max }\right]=[0.0,2.0]$ refers to a structure in which all risk is transferred to annuitants, i.e., to a non-capped PLLA.

The results in Table 5 show that for a 60-year old male individual entering a PLLA contract allowing for a maximum $10 \%$ variation in annuity payments the longevity floor price reduces from 1.28 in the non-capped equivalent structure to 0.90 $(-29.4 \%)$. Stated differently, limiting the longevity risk borne by annuitants reduces the price discount to be offered in PLLAs when compared to both a traditional level annuity and the uncapped PLLA. Our results also show that the fair value of the longevity floor and, consequently, the fair value of the capped PLLA converges steadily to that of the equivalent uncapped annuity design the larger the fraction of unexpected mortality improvements that is transferred to annuitants. We can observe that allowing for a maximum of $20 \%$ variation in annuity benefits transfers close to $90 \%$ of the longevity risk to annuitants. ${ }^{15}$ Partial risk-sharing annuity structures are an interesting alternative to cope with longevity risk when compared to, for instance, expensive longevity-linked reinsurance arrangements, increasing pricing loadings which reduce the attractiveness of annuity contracts or allocating more solvency capital.

\footnotetext{
15 We conducted a sensitivity analysis on the impact of the GIR on longevity option prices and concluded that for non-participating LLAs, higher guaranteed interest rates reduce the fair value of the embedded options because of the discounting effect. Owing to space constraints, these results are not reported in the paper but can be obtained from the authors upon request.
} 
Table 6 WTP (EFLA) for PLLAs (notes: GIR=0 percent; Market price of longevity risk parameter equal to 0.3 )

\begin{tabular}{|c|c|c|c|c|c|c|c|c|c|c|}
\hline \multicolumn{2}{|c|}{ Parameters } & \multicolumn{9}{|l|}{ Age } \\
\hline$\beta$ & $\gamma$ & 50 & 55 & 60 & 65 & 70 & 75 & 80 & 85 & 90 \\
\hline \multirow[t]{3}{*}{0.98} & 2 & 33.90 & 28.80 & 23.94 & 19.42 & 15.25 & 11.58 & 8.47 & 5.94 & 3.98 \\
\hline & 5 & 32.29 & 27.43 & 22.81 & 18.50 & 14.53 & 11.03 & 8.07 & 5.65 & 3.79 \\
\hline & 10 & 31.53 & 26.78 & 22.26 & 18.06 & 14.18 & 10.77 & 7.87 & 5.52 & 3.70 \\
\hline \multirow[t]{3}{*}{0.96} & 2 & 33.56 & 28.34 & 23.37 & 18.75 & 14.51 & 10.79 & 7.63 & 5.51 & 3.81 \\
\hline & 5 & 31.00 & 26.69 & 21.72 & 17.17 & 13.94 & 10.31 & 7.20 & 5.08 & 3.58 \\
\hline & 10 & 29.93 & 25.60 & 21.74 & 17.15 & 13.00 & 10.27 & 7.18 & 4.97 & 3.57 \\
\hline \multirow[t]{3}{*}{0.94} & 2 & 33.03 & 27.74 & 22.71 & 18.03 & 14.01 & 10.24 & 6.95 & 5.08 & 3.72 \\
\hline & 5 & 29.23 & 25.63 & 20.44 & 16.65 & 13.28 & 9.58 & 6.87 & 4.91 & 3.53 \\
\hline & 10 & 28.62 & 24.59 & 21.28 & 16.57 & 12.74 & 9.76 & 6.75 & 4.87 & 3.51 \\
\hline
\end{tabular}

\subsection{Individual preferences and willingness-to-pay for the contract}

We consider individuals' preferences towards risk and evaluate the willingness-topay (WTP) for the contracts by computing the fair value of the EFLA that delivers the same lifetime utility as the PLLA. Table 6 reports the mean EFLA results for participating PLLAs considering three alternative time preference and risk aversion parameters. We assume the market price of longevity risk parameter is $\lambda=0.3$ and the guaranteed interest rate is $i=0 \%$. For every age, the WTP results compare with that of a level annuity. For instance, the WTP for a non-participating LLA for a 65-year old male policyholder with medium risk aversion $(\gamma=5)$ and normal ( $\beta=0.96)$ intertemporal preference is 16.31 , a price that represents $95.6 \%$ of that of the corresponding level annuity. Non-participating PLLAs transfer all systematic longevity risk to policyholders and do not offer the upside potential of positive financial developments, reducing the utility drawn by high risk aversion and impatient annuitants from uncertain and potentially volatile annuity benefits. Consequently, policyholders will only be willing to enter the contract at a given price discount relative to a standard level annuity. Alternatively, they would be willing to pay the same premium in exchange for a higher payout stream when compared to fixed annuities.

The results in Table 6 also show that, for all ages and time preference and risk aversion parameters, the WTP for a participating PLLAs is higher than for a nonparticipating structure. For instance, the WTP for a PLLA for a 60 -year old male policyholder with low risk aversion $(\gamma=2)$ and low $(\beta=0.98)$ intertemporal preference is 23.94. Policyholders value favorably the possibility to profit from positive financial market developments (negative scenarios are bounded by the guaranteed interest rate) despite the increased variability in annuity benefits from the combined effect of longevity and financial market risks. The WTP for participating PLLAs is higher the lower the guaranteed interest rate. In a low (zero) interest rate environment, the upside potential carried by a PLLA is more valued and can be sufficient to offset the disutility generated by lower annuity payments if observed survival 
Table 7 WTP (EFLA) for participating PLLA with lifecycle asset allocation strategy (notes: GIR = 0 percent; Market price of longevity risk parameter equal to 0.3 )

\begin{tabular}{|c|c|c|c|c|c|c|c|c|c|c|}
\hline \multicolumn{2}{|c|}{ Parameters } & \multicolumn{9}{|l|}{ Age } \\
\hline$\beta$ & $\gamma$ & 50 & 55 & 60 & 65 & 70 & 75 & 80 & 85 & 90 \\
\hline \multirow[t]{3}{*}{0.98} & 2 & 35.93 & 30.49 & 25.33 & 20.52 & 16.10 & 12.22 & 8.92 & 6.24 & 4.17 \\
\hline & 5 & 33.88 & 28.75 & 23.88 & 19.35 & 15.19 & 11.52 & 8.41 & 5.88 & 3.93 \\
\hline & 10 & 32.75 & 27.79 & 23.08 & 18.70 & 14.67 & 11.13 & 8.12 & 5.68 & 3.80 \\
\hline \multirow[t]{3}{*}{0.96} & 2 & 35.57 & 30.01 & 24.72 & 19.81 & 15.32 & 11.38 & 8.03 & 5.79 & 3.99 \\
\hline & 5 & 32.53 & 27.97 & 22.74 & 17.96 & 14.56 & 10.77 & 7.50 & 5.28 & 3.72 \\
\hline & 10 & 31.08 & 26.57 & 22.54 & 17.76 & 13.45 & 10.62 & 7.41 & 5.12 & 3.67 \\
\hline \multirow[t]{3}{*}{0.94} & 2 & 35.01 & 29.37 & 24.02 & 19.04 & 14.79 & 10.80 & 7.32 & 5.33 & 3.90 \\
\hline & 5 & 30.67 & 26.86 & 21.40 & 17.41 & 13.88 & 10.00 & 7.17 & 5.10 & 3.66 \\
\hline & 10 & 28.45 & 24.52 & 21.29 & 16.63 & 12.82 & 9.85 & 6.83 & 4.95 & 3.58 \\
\hline
\end{tabular}

prospects are higher than anticipated. Similar conclusions were obtained for participating and non-participating capped PLLAs and deferred annuity structures. We conducted a sensitivity analysis on the impact of the GIR on the WTP for PLLAs and concluded that for participating contracts higher guaranteed interest rates reduce the initial benefits and diminish the expected distributed surplus and upside potential when compared to a standard fixed annuity.

\subsection{Sensitivity to asset allocation}

In the baseline scenario we assumed a static conservative asset allocation strategy. In real world investment environments, this involves setting target allocations for the asset classes (e.g., stocks, bonds) in which the annuity provider's portfolio is invested and periodically rebalancing to match the original allocations when, for instance, there are coupon/dividend payments and/or existing bonds mature and new issues start to be traded. This is often a buy-and-hold strategy. In this section we investigate the sensitivity of the results to alternative asset allocations, particularly a more aggressive lifecycle strategy. This strategy allocates $70 \%$ of the portfolio to stocks at contract inception and the remaining to coupon bonds, with the risky assets gradually reduced to $30 \%$ at the end of a 30-year investment horizon, common for all contracts. As the allocation to stocks is reduced, the allocation to debt instruments is increased, with the provider switching to the baseline conservative asset allocation strategy at the end of the horizon. ${ }^{16}$ Milevsky and Promislow [50] suggest the need for holding a substantial stock allocation in retirement portfolios to enhance pension income.

\footnotetext{
16 An alternative formulation could be to pursue a more aggressive lifecycle strategy up to a fixed old age (e.g., 90 years old), resuming from that age on to a static conservative asset allocation strategy.
} 
Table 7 reports the mean WTP (EFLA) results for the lifecycle asset allocation strategy for participating LLAs considering alternative time preference and risk aversion parameters. The results suggest that augmenting the exposure to stock markets early in the contract's life increases the expected annuity payments and benefit volatility. The enhanced right tail of the portfolio return distribution is positively valued by policyholders, particularly patient and low risk aversion individuals who appreciate the possibility of higher investment returns. In contrast, the increased variability in portfolio returns generated by the lifecycle asset allocation strategy acts against impatient and high-risk aversion annuitants since it makes it more difficult for retirement planning compared to a conservative (low risk) asset allocation strategy.

The PLLA shares risk between the provider and the individual but guarantees a (variable) benefit for life, i.e., it is a product that provides partial protection against investment and longevity risk preventing individuals from outliving their assets. This contrasts with products with pooled benefits (e.g., group self annuitisation (GSA) arrangements, pooled annuity funds, mortality-linked funds, annuity overlay funds, tontines) in which financial and longevity risks are shared among participants but no guarantees are explicitly provided by the insurer. In PLLA, the annuitant is however subject to the risk of bankruptcy of the annuity provider, that is not trivial considering the long duration of annuity contracts, but that can be mitigated if guaranteed interest rates are low and the obligations are backed by adequate reserves and capital of the provider. ${ }^{17}$ The bankruptcy risk can also be addressed by a Government guarantee (like in Chile), which can be partial and include a reasonable amount of coinsurance by annuitants [61]. ${ }^{18}$

\section{Conclusion}

Participating longevity-linked life annuities are insurance products sharing longevity and financial risks between the provider and the individual. They depart from traditional level annuities in that they offer only partial guarantees and from non-insurance pooling arrangements like group self-annuitisation, pooled annuity funds, mortality-linked funds, annuity overlay funds and modern tontines in which no financial or longevity guarantees are explicitly provided by an insurer and risks are merely pooled among participants. PLLAs include embedded auto-executable longevity and financial options allowing the provider to periodically revise annuity payments if observed survivorship and portfolio outcomes deviate from expected (or guaranteed) values at contract initiation. In this paper we empirically investigated the design and valuation of index-type participating longevity-linked life annuities using Taiwanese (mortality, yield curve and stock market) data from January 1980 to June 2019, considering for both immediate and deferred, capped and uncapped participating

\footnotetext{
17 See, e.g., Chen and Suchanecki [21] and Chamboko and Bravo [19, 20].

18 In Chile, this guarantee is backed by budgetary resources, but there are other possibilities including the introduction of a small fund financed by the industry.
} 
and non-participating annuity structures. We build on previous work by considering a novel methodological approach for the modelling of longevity risk based on a Bayesian Model Ensemble of six parametric single population Generalised AgePeriod-Cohort stochastic mortality models, all of which probabilistically contribute towards projecting future age-specific mortality rates, survival probabilities and PLLA prices. The BME approach allows us to incorporate additional sources of risk not captured in a single model framework and to explicitly account for model risk in the valuation setup, mitigating errors resulting from flawed assumptions, bias or errors in the data. Additionally, we empirically investigate the impact of alternative (lifecycle) asset allocation strategies on the valuation results considering for alternative risk aversion and time impatience coefficients.

Considering for alternative cohorts and values of the market price of longevity risk, our empirical results show that the fair value of the longevity options embedded in PLLAs in which benefits can be reduced if the observed (male) population survival prospects are higher than predicted can be as high as nearly $6 \%$ of the pure premium of a corresponding conventional level annuity. ${ }^{19}$ Longevity options are asymmetric contracts in which the holder (buyer) has the right (but not the obligation) to buy or sell the underlying asset at some time in the future. This allows the holder of the option (the annuity provider in this case) to exercise the contract only when it is profitable to do so, whereas the writer (the policyholder) of the contract is in a weaker position since its obligations are contingent to the buyer's decision to exercise or not the option. For this privilege, the option buyer must pay an up front, non-returnable premium (option price) to the option writer. Taking this argument into the PLLA arena, our empirical results suggest that a policyholder entering a contract including an option to reduce future payments if the actual survivorship rates are higher than expected should be offered at a price up to $6 \%$ cheaper than that of a corresponding level annuity to compensate for the risk of adverse longevity developments. Alternatively, it should be given a higher annuity benefit for the same price. Our results show, as expected, that this relative "price discount" (longevity option premium) increases with the maturity of the contract, i.e., it is higher the younger the policyholder at contract inception, declining then with age, and that it increases with the market price of longevity risk (as measured by the Wang distortion operator). The results also show that the variability of the PLLA prices is higher for contracts initiated early in life, an outcome that is explained by the increased uncertainty on the remaining lifetime at these ages. The empirical results for capped PLLA contracts initiated at different ages sharing longevity risk only and limiting the upside potential and the downside risk to $20 \%$ of the initial annuity benefit transfer close to $90 \%$ of the longevity risk to annuitants, while allowing insurers to release a substantial fraction of the capital buffer they are required to hold to back guarantees in traditional annuity portfolios and to limit default risk. Stated differently, abstracting from basis risk, allowing for a $20 \%$ maximum variation in annuity benefits is sufficient to transfer most of the longevity risk associated with

\footnotetext{
19 Similar results were obtained for females, with slightly lower volatility in expected longevity developments and embedded PLLA option prices.
} 
unexpected longevity developments in the population when compared an unbounded contract, mitigating also the uncertainty in annuitants' payments and consumption possibilities, a desirable feature especially at very old ages. Compared to immediate annuities, deferred PLLA contracts, eventually including for caps and floors, are an interesting solution for the payout phase of pension schemes since in exchange for a significantly smaller premium they provide protection against ones' outliving their (financial, housing, pension) wealth at old ages. The empirical results show that individuals with low risk aversion and low intertemporal preference value positively the chance to profit from right tail financial market developments in participating PLLAs (negative scenarios are bounded by the non-negative guaranteed interest rate) despite increased variability in annuity benefits. The empirical results on the adoption of a riskier lifecycle asset allocation strategy early in the contract's life show that expected annuity payments and benefit volatility increase, when compared to a more conservative asset allocation strategy, an outcome that is positively valued by patient and low risk aversion policyholders who appreciate the chance of benefiting from the upside potential of financial markets.

The development of innovative annuity contracts in which biometric and financial market risk is shared between annuity providers and policyholders is an important development for consumers, annuity providers and for the society as whole, tackling some of the demand- and supply-side constraints which prevent individuals from annuitizing their retirement wealth, getting longevity risk protection and receiving an adequate retirement income, offering providers an incentive to write new contracts in an environment characterized by low and persistent negative yields in which guarantees are costly and reinsurance or capital market solutions for longevity risk are scarce and expensive. Further research should investigate the robustness of these results against changes in the method used to risk-neutralize the innovations in the stochastic mortality model used for forecasting or to account for the longevity risk premium (e.g., by adopting a cost of capital Solvency II approach). Further research is also needed to design and valuate alternative methods to directly share longevity risk between the provider and annuitants (e.g., by linking the benefits to periodically revised annuity factors). Further research is also needed to develop alternative methods for the valuation of the financial and longevity options embedded in PLLAs.

Finally, in the context of the ongoing COVID-19 pandemic outbreak, it is important to briefly discuss the impact of adverse mortality and morbidity shocks on insured annuity and pension scheme portfolios. If in the early stages of the pandemic the disease has predominantly impacted mortality at high ages, it remains to be seen whether the catastrophic mortality event has the potential to permanently and severely affect human longevity prospects at all ages, in an uniform or heterogeneous way across socioeconomic groups, either directly or indirectly as a consequence of the containment measures adopted to halt the spread of the disease, or if it is just a temporary shock that accelerated the termination of life of certain groups with pre-existing significant co-morbidities. The ultimate longevity impact of COVID-19 is likely to depend on factors such as the timing and effectiveness of vaccine and therapy solutions, improved attention to public health care and social improvements, or a structural change in policyholder's behaviour and risk profile. In any case, for policyholders the mortality shock increased the fair value of call options embedded 
in symmetric PLLA and similar annuity contracts sharing mortality and longevity risk with the provider, enhancing their return on investment when compared to fixed annuities. For the actuarial community, the mortality shock has also heightened the importance of departing from a single model approach to predict future mortality rates towards the use of model combinations to better approximate the actual data generation process and its multiple sources of risk, reducing model risk, improving the out-of-sample forecasting accuracy, providing a more realistic assessment of forecast uncertainty. To this end, further research is required to investigate alternative ways of determining the optimal model set and model weights. Moreover, the pandemic outbreak highlights the importance of modelling and managing mortality and longevity risk accounting for both negative and positive jumps in mortality rates, possibly of different size (see, e.g., Bravo and Nunes [13] for a recent proposal using an affine-jump diffusion framework including double asymmetric exponentially distributed jumps).

Acknowledgements The author would like to express his gratitude to the editor and to two anonymous referees for his or her careful review and insightful comments, that helped strengthen the quality of the paper. We thank also the suggestions and remarks from participants at the CAPSI 2020 Conference, Porto. The author was supported by Portuguese national science funds through FCT under the project UIDB/04152/2020-Centro de Investigação em Gestão de Informação (MagIC).

\section{References}

1. Alho J, Bravo J M, Palmer E (2013) Annuities and life expectancy in NDC. In: Holzmann R, Palmer E, Robalino D (eds) Nonfinancial defined contribution Pension Schemes in a Changing Pension World, Volume 2, Gender, Politics, and Financial Stability, pp 395-436

2. Ayuso M, Bravo JM, Holzmann R (2017) Addressing longevity heterogeneity in pension scheme design. J Financ Econ 6(1):1-21

3. Blake D, Cairns A, Dowd K, MacMinn R (2006) Longevity bonds: financial engineering, valuation, and hedging. J Risk Insur 73(4):647-672

4. Blake D, Cairns AJG, Dowd K (2003) Pensionmetrics II: stochastic pension plan design during the distribution phase. Insur Math Econ 33:29-47

5. Bovenberg L, Bilsen S, Mehlkopf R (2015) Personal pensions with risk sharing affordable, adequate and stable private Pensions in Europe. Netspar Discussion Paper Series 03-2015

6. Boyer M, Stentoft L (2013) If we can simulate it, we can insure it: an application to longevity risk management. Insur Math Econ 52(1):35-45

7. Boyle P, Hardy M, MacKay A, Saunder D (2015) Variable payout annuities. Society of Actuaries, December

8. Bräutigam M, Guillén M, Nielsen JP (2017) facing up to longevity with old actuarial methods: a comparison of pooled funds and income tontines. The Geneva papers on risk and insurance-issues and practice $42(3): 406-422$

9. Bravo JM (2019) Funding for longer lives: retirement wallet and risk-sharing annuities. Ekonomiaz 96(2):268-291

10. Bravo JM, Silva CM (2006) Immunization using a stochastic process independent multifactor model: the Portuguese experience. J Bank Financ 30(1):133-156

11. Bravo JM, El Mekkaoui de Fretas N (2018) Valuation of longevity-linked life annuities. Insur Math Econ 78:212-229

12. Bravo JM, Herce JA (2020) Career breaks, broken pensions? Long-run effects of early and latecareer unemployment spells on pension entitlements. J Pension Econ Financ. https://doi.org/10. $1017 / \mathrm{S} 1474747220000189$ 
13. Bravo JM, Nunes JPV (2021) Pricing longevity derivatives via Fourier transforms. Insur Math Econ 96:81-97

14. Bravo JM, Ayuso M, Holzmann R, Palmer E (2021) Addressing the life expectancy gap in Pension policy. Insur Math Econ 99:200-221. https://doi.org/10.1016/j.insmatheco.2021.03.025

15. Bravo J M, Corte-Real P, Silva C M (2009) Participating life annuities incorporating longevity risk sharing arrangements. Working Paper, available from rdpc.uevora.pt

16. Brouhns N, Denuit M, Vermunt J (2002) A Poisson log-bilinear regression approach to the construction of projected lifetables. Insur Math Econ 31:373-393

17. Cairns A, Blake D, Dowd K, Coughlan G, Epstein D, Ong A, Balevich I (2009) A quantitative comparison of stochastic mortality models using data from England and Wales and the United States. N Am Actuarial J 13(1):1-35

18. Cairns AJG, Blake D, Dowd K (2006) A two-factor model for stochastic mortality with parameter uncertainty: theory and calibration. J Risk Insur 73:687-718

19. Chamboko R, Bravo JM (2016) On the modelling of prognosis from delinquency to normal performance on retail consumer loans. Risk Manag 18(4):264-287

20. Chamboko R, Bravo JM (2020) A multi-state approach to modelling intermediate events and multiple mortgage loan outcomes. Risks 8:64. https://doi.org/10.3390/risks8020064

21. Chen A, Suchanecki M (2007) Default risk, bankruptcy procedures and the market value of life insurance liabilities. Insur Math Econ 40(2):231-255

22. Chen A, Hieber P, Klein JK (2019) Tonuity: a novel individual-oriented retirement plan. ASTIN Bull 49(1):5-30

23. Chen A, Rach M (2019) Options on tontines: an innovative way of combining tontines and annuities. Insur Math Econ 89:182-192

24. Currie I (2006) Smoothing and forecasting mortality rates with P-splines. London: Institute and Faculty of Actuaries. https://www.actuaries.org.uk/documents/smoothing-and-forecasting-morta lity-rates-p-splines-handouts. Accessed 20 Jul 2018

25. Denuit M, Goderniaux AC (2005) Closing and projecting life tables using log-linear models. Bull Swiss Assoc Bull Swiss Assoc Actuaries 1:29-48

26. Denuit M, Haberman S, Renshaw A (2011) Longevity-indexed life annuities. N Am Actuarial J 15:97-111

27. Denuit M, Haberman S, Renshaw A (2015) Longevity-contingent deferred life annuities. J Pension Econ Financ 14(3):315-327

28. Devolder P, de Valeriola S (2019) Between DB and DC: optimal hybrid PAYG pension schemes. Eur Actuarial J 9:463-482

29. Diez F, Korn R (2020) Yield curve shapes of Vasicek interest rate models, measure transformations and an application for the simulation of pension products. Eur Actuarial J 10:91-120

30. Donnelly C (2015) Actuarial fairness and solidarity in pooled annuity funds. ASTIN Bull 45(1):49-74

31. Donnelly C, Guillén M, Nielsen J (2013) Exchanging uncertain mortality for a cost. Insur Math Econ 52:65-76

32. Donnelly C, Guillén M, Nielsen J (2014) Bringing cost transparency to the life annuity market. Insur Math Econ 56:14-27

33. Donnelly C, Young J (2017) Product options for enhanced retirement income. Br Actuar J 22(3):636-656

34. Dowd K, Cairns A, Blake D, Coughlan G, Epstein D, Khalaf-Allah M (2010) Backtesting stochastic mortality models. N Am Actuar J 14(3):281-298

35. Fullmer RK, Sabin MJ (2019) Individual tontine accounts. J Account Financ 19:8. https://doi. org/10.33423/jaf.v19i8.2615

36. Fung M, Ignatieva K, Sherris M (2019) Managing systematic mortality risk in life annuities: an application of longevity derivatives. Risks 7(1):2. https://doi.org/10.3390/risks7010002

37. Haberman S, Renshaw A (2011) A comparative study of parametric mortality projection models. Insur Math Econ 48:35-55

38. Hanewald K, Piggott J, Sherris M (2013) Individual post-retirement longevity risk management under systematic mortality risk. Insur Math Econ 52:87-97

39. Holzmann R, Ayuso M, Alaminos E, Bravo JM (2019) Life cycle saving and dissaving across three-tier income groups: starting hypotheses, refinement through literature review, and ideas of international empirical testing. IZA Discussion Paper No. 12655 
40. Human Mortality Database (2019) University of California, Berkeley (USA), and Max Planck Institute for Demographic Research (Germany)

41. Hunt A, Blake D (2021) On the structure and classification of mortality models. N Am Actuar J 25(sup1):S215-S234. https://doi.org/10.1080/10920277.2019.1649156

42. Hunt A, Villegas AM (2015) Robustness and convergence in the Lee-Carter model with cohort effects. Insur Math Econ 64:186-202

43. Kass RE, Raftery AE (1995) Bayes factors. J Am Stat Assoc 90:773-795

44. Lüthy H, Keller PL, Binswangen K, Gmur B (2001) Adaptive algorithmic annuities. Mitteilungen Schweizerischen Aktuarvereinigung 2:123-138

45. Maurer R, Mitchell O, Rogalla R, Kartashov V (2013a) Lifecycle portfolio choice with systematic longevity risk and variable investment-linked deferred annuities. J Risk Insur 80(3):649-676

46. Maurer R, Rogalla R, Siegelin I (2013b) Participating payout life annuities: lessons from Germany. ASTIN Bull 43(2):159-187

47. Milevsky M (2013) Life annuities: optimal products for retirement income. The Research Foundation of the CFA Institute. www.cfapubs.org

48. Milevsky MA, Salisbury TS (2015) Optimal retirement income tontines. Insur Math Econ 64:91-105

49. Milevsky MA, Salisbury TS (2016) Equitable retirement income tontines: mixing cohorts without discriminating. ASTIN Bull 46(3):571-604

50. Milevsky MA, Promislow SD (2001) Mortality derivatives and the option to annuitise. Insur Math Econ 29(3):299-318

51. Mitchell OS, Poterba JM, Warshawsky MJ, Brown JR (1999) New evidence on the money's worth of individual annuities. Am Econ Rev 89(5):1299-1318

52. Olivieri A, Pitacco E (2020) Linking annuity benefits to the longevity experience: alternative solutions. Ann Actuar Sci 14(2):316-337

53. Piggott J, Valdez E, Detzel B (2005) The simple analytics of pooled annuity funds. J Risk Insur 72(3):497-520

54. Pitacco E (2019) Heterogeneity in mortality: a survey with an actuarial focus. Eur Actuar J 9(1):3-30

55. Plat R (2009) On stochastic mortality modeling. Insur Math Econ 45:393-404

56. Qiao C, Sherris M (2013) Managing systematic mortality risk with group self-pooling and annuitization schemes. J Risk Insur 80(4):949-974

57. Raftery A, Gneiting T, Balabdaoui F, Polakowski M (2005) Using Bayesian model averaging to calibrate forecast ensembles. J Am Meteorol Soc 133:1155-1174

58. Renshaw A, Haberman S (2006) A cohort-based extension to the Lee-Carter model for mortality reduction factors. Insur Math Econ 38(3):556-570

59. Renshaw AE, Haberman S (2003) Lee-Carter mortality forecasting with age specific enhancement. Insur Math Econ 33:255-272

60. Richter A, Weber F (2011) Mortality-indexed annuities: managing longevity risk via product design. N Am Actuar J 15:212-236

61. Rocha R, Thorburn C (2007) Developing annuities markets: the experience of Chile. The International Bank for Reconstruction and Development/The World Bank, Washington DC

62. Saha MV, Davis RE, Hondula DM (2014) Mortality displacement as a function of heat event strength in 7 US cities. Am J Epidemiol 179(4):467-74

63. Sergio AT, Lima TP, Ludermir TB (2016) Dynamic selection of forecast combiners. Neurocomputing 218:37-50

64. Simões C, Oliveira L, Bravo JM (2021) Immunization strategies for funding multiple inflationlinked retirement income benefits. Risks 9(4):60. https://doi.org/10.3390/risks9040060

65. Stamos M (2008) Optimal consumption and portfolio choice for pooled annuity funds. Insur Math Econ 43(1):56-68

66. Valdez E, Piggott J, Wang L (2006) Demand and adverse selection in a pooled annuity fund. Insur Math Econ 39(2):251-266

67. Vasicek O (1977) An equilibrium characterization of the term structure. J Financ Econ 5:177-88

68. Vaupel JW, Manton KG, Stallard E (1979) The impact of heterogeneity in individual frailty on the dynamics of mortality. Demography 16(3):439-54

69. Villegas AM, Millossovich P, Kaishev VV (2018) StMoMo: an R package for stochastic mortality modelling. J Stat Softw 84(3):1-38 
70. Wang S (1996) Premium calculation by transforming the layer premium density. ASTIN Bull 26(1):71-92

71. Wang S (2000) A class of distortion operations for pricing financial and insurance risks. J Risk Insur 67:15-36

72. Wang S (2002) A universal framework for pricing financial and insurance risks. ASTIN Bull 32(2):213-234

Publisher's Note Springer Nature remains neutral with regard to jurisdictional claims in published maps and institutional affiliations. 